The Sentinel Research Network of leDEA

A prospective cohort among people living with HIV 
Table of content

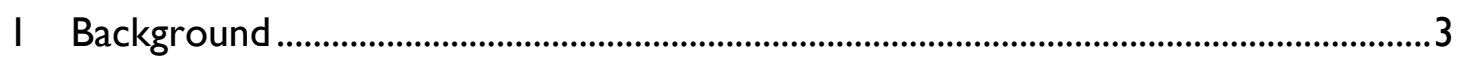

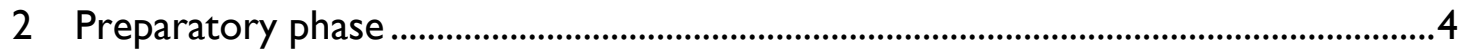
components 4

2.I Cultural modification for substance use and mental health SRN survey

2.2 List of required devices

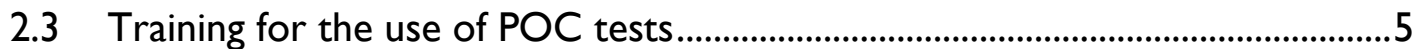

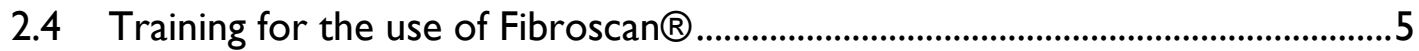

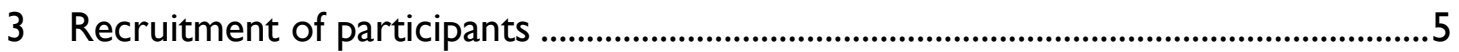

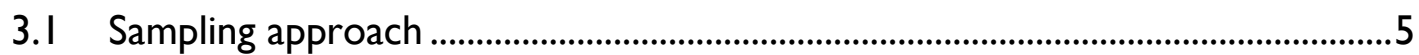

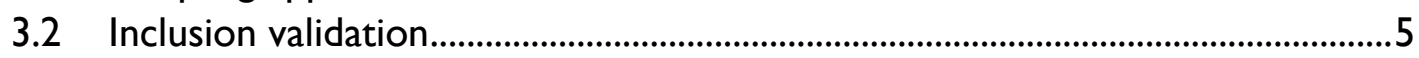

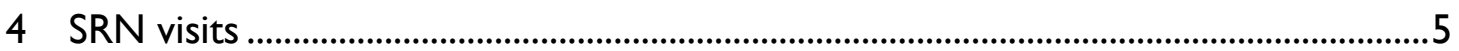

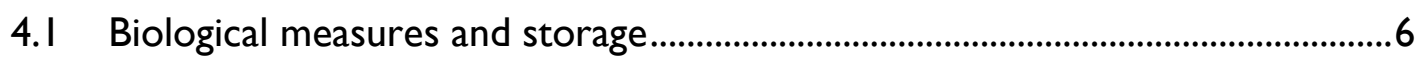

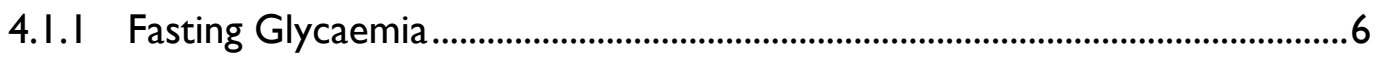

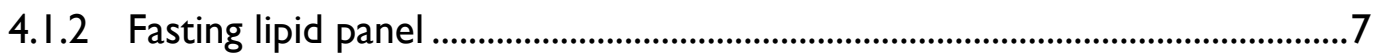

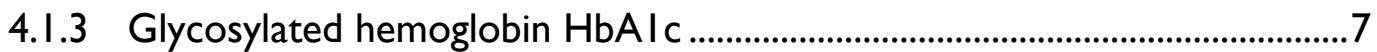

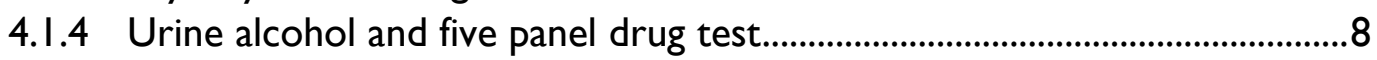

4.I.5 HBV, HCV rapid diagnostic tests (Only at baseline)................................... 10

4. I.6 Blood count/platelets, transaminases, creatinine (only at baseline).......... I I

4.1.7 Blood sampling using a DBS card (5 spots) ................................................ I I

4.1.8 Transport of specimen to the local laboratories ......................................... 12

4.1.9 Specimen storage (DBS, Blood and Urine) (at baseline) ............................ 12

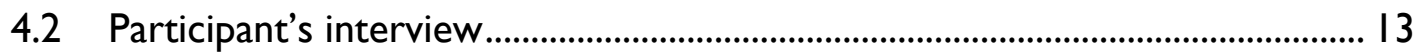

4.2.I Inclusion/ Exclusion............................................................................................. 13

4.2.2 Locator information and alternative contact personal details ................... I I

4.2.3 Demographics ......................................................................................... 13

4.2.4 Medical History (self-report) ................................................................. 13

4.2.5 Chart Review Medical History ………....................................................... 13

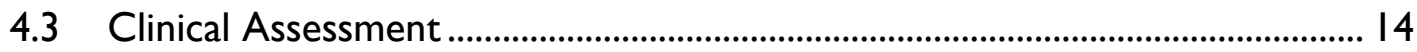

4.3.I Anthropometric measures............................................................................. 14

4.3.2 Liver stiffness and CAP measures (Fibroscan ${ }^{\circledR}$ ) .......................................... 17

4.4 Screening questionnaires administration ......................................................... 18

4.4.I Mental Health disorders .............................................................................. 18

4.4.2 Alcohol and Substance Use Disorder Screening.......................................... 21

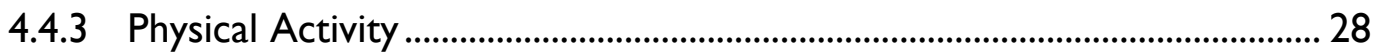

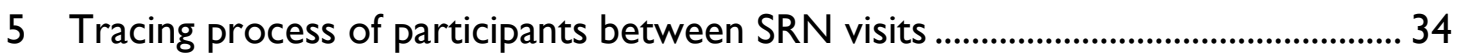

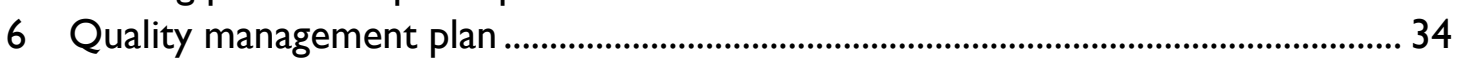

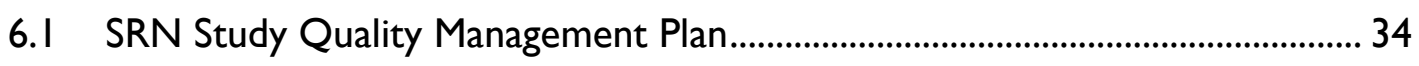

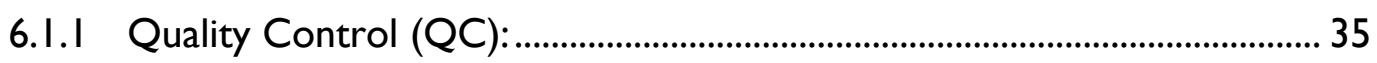

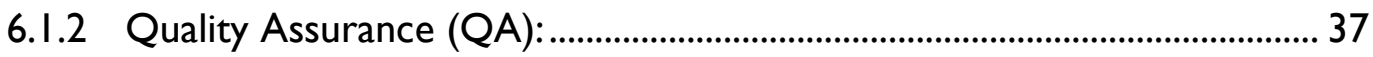

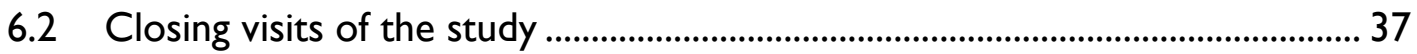

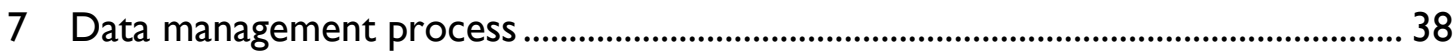

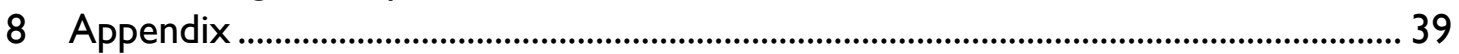




\section{Table of appendix}

Appendix I: Standard Operating Procedure for Linguistic Validation ............................ 39

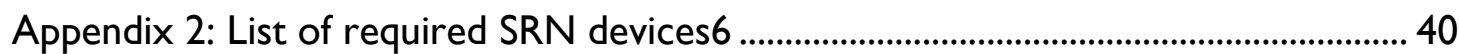

Appendix 3 :Translation and adaptation to Specific Languages, Cultures and Standards

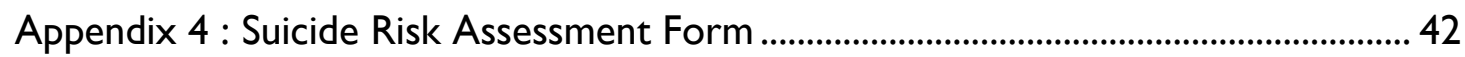

Appendix 5 : Response Card / WHO ASSIST V3.0/3.1 .................................................... 45 
The aim of the Sentinel Research Network (SRN) is to establish a network of research sites to capture and analyze data among PLHIV in LMICs in a standardized way. Through this network, we further seek to implement studies on cardiovascular risk factors, mental health, alcohol and other substance use disorders, as well as liver disease prevalence and associated factors among PLHIV accessing care in LMICs.

To this end, in intend to create a "sentinel" cohort nested in the pre-existing regional networks of the International epidemiologic Databases to Evaluate AIDS (leDEA) cohorts based in LMICs. A total of six leDEA research sites located in Brazil, Côte d'Ivoire, India, Kenya, Rwanda and Zambia are expected to recruit a total of I 375 people with HIV $\geq 40$ years and on ART $\geq 6$ months. These participants will be assessed at baseline for various chronic conditions and their risk factors, including diabetes, dyslipidemia, hypertension, drug and alcohol abuse, as well as chronic liver diseases, through standardized questionnaires and non-to-minimally invasive "bedside" screening tests. Follow-up visits are planned at month six and month twelve for reassessment of these chronic conditions. Data prospectively collected through the SRN will be merged with pre-existing HIV-related data routinely collected through leDEA cohorts.

The present manual intends to facilitate the implementation of SRN activities at site level. A first part includes information on the preparatory phase and selection of the study population. A second part includes the procedures for recruiting study participants. A third part contains detailed information on the SRN visits including questionnaires administration on alcohol and substance use, mental health disorders, participant's interview, use of Fibroscan ${ }^{\circledR}$ and biological measures within the framework of the project. Furthermore, a tracing and monitoring process of SRN participants is also proposed in this manual.

These procedures should be adapted by each SRN sites according to their specificities as long as they stay in line with the master SRN protocol. 


\section{Preparatory phase}

Questionnaires on alcohol and substance use, mental health disorder and physical activity survey (i.e., AUDIT, ASSIST and GPAQ) will be tested in a preparatory survey in order for training and adaption to the context of the SRN site. Information needed to conduct this preparatory survey is presented below with Standard Operating Procedure for Linguistic Validation attached in appendix I. Furthermore, information on required devices, training for the use of POC tests and Fibroscan ${ }^{\circledR}$ prior the study is also discussed in this section.

\section{I Cultural modification for substance use and mental health SRN survey components}

\section{Purpose :}

- To explore participant's understanding and interpretation of mental health and substance userelated questions

- To determine the feasibility of asking participants' sensitive mental health and substance userelated questions

- To test mental health and substance use-related scales.

Scope: This document provides guidance for the implementation of brief interviews as part of the preparatory survey of the SRN baseline and follow-up visits.

Participant eligibility: All participants for the preparatory survey should be recruited from the HIV clinic using the same enrollment criteria as for the SRN study.

Number of participants: 5 participants per SRN instrument.

\section{PARTICIPANT RECRUITMENT}

Step I: Recruitment strategy may include asking research staff to approach participants and inform potential participants about the pre-pilot. Those recruiting potential participants for the pre-pilot must inform potential participants that participation in the pre-pilot is voluntary, participation (or choosing not to participate) will not affect treatment, and clinic staff will not be part of the study.

Step 2: Research staff conduct a face-to-face interview on same day or follow-up with participant to schedule interview.

\section{PROCEDURES FOR ADMINISTERING INTERVIEW}

Please see Standard Operating Procedure for Linguistic Validation in the appendix I.

\subsection{List of required devices}

All devices required for the SRN study must be available prior enrolling the first SRN participant (See appendix 2). For lipid and HbAlc assays, if the POC device is too expensive or hardly available, SRN sites can alternatively decide to perform local standard laboratory tests. 


\subsection{Training for the use of POC tests}

To standardize staff training and to ensure uniformity in data collection and robustness of data analysis, local site staff will need to be trained on the use of the POC test, prior to the enrollment phase.

\subsection{Training for the use of Fibroscan ${ }^{\circledR}$}

Prior starting the SRN study, a dedicated training process will be organized by each participating region at site level for the use of the FibroScan $\AA$ device. A minimum of 50 procedures must be carried out by each research assistant in the clinic before the study enrollment begins.

\section{Recruitment of participants}

\section{I Sampling approach}

The study sample will be based on a systematic sampling approach in order to have a representative sample of people who have 40 years and older and who have been on ARV treatment for 6 months or more in the HIV clinic. This sampling procedure requires a prior knowledge of the number of participants that can be enrolled during a daily "Baseline SRN assessment" activity (which should vary between four and seven participants per day). During the "pre-enrollment visit" and for a given day of HIV care visits, doctors from the SRN site could propose participation to their patients using the following procedure for example: the SRN research assistant in charge of inclusions selects eligible participants from the total number of patients who come for routine visits by choosing a random starting point (using a cube or the excel random function) and selecting other members after a fixed 'sampling interval'. The sampling interval $(n)$ is calculated by dividing the total daily number of patients by the desired sample size per day. To begin, the SRN investigator selects a random starting point between the first patient and the $(n)$ patient in the sampling interval $(I-n)$.

\subsection{Inclusion validation}

Eligible participants will be selected for inclusion in the study during their routine clinical care visits and invited to enroll in the study. Once screened for eventual inclusion criteria, they will be informed of the risks and benefits to participate in the study. If an exclusion criterion is present, the research assistant will be asked to propose participation to the next eligible patient listed on the daily routine visit list. Those confirming their interest to participate will be asked to provide written informed consent in a manner consistent with local institutional policy. A research assistant trained on SRN consent and study procedures will provide information about the study to eligible individuals in local languages. Those who consent to be included will be scheduled for a baseline study visit.

\section{SRN visits}

For all participant encounters, we will ensure that study staff, does not interview anyone they know personally (e.g., a friend or family member). All visits, including informed consent, biological and anthropometric measures, medical history and standardized questionnaires will be conducted in a private examination room with the door closed. If the participant has a friend or family member present at the clinic visit, we will ask that the friend or family member leave the room for the interview, unless it is the participant's preference that the friend or family member stay in the room for the interview. We will make clear to the participant that we will be asking questions that may be personal or sensitive.

Note: The SRN visits are scheduled at baseline, M6 and MI2. 


\section{I Biological measures and storage}

These measures to be adapted according to SRN Sites. They should be carried out fasting, ideally before filling in the questionnaires and taking the anthropometric measurements. However, if there are two or more participants in waiting, it may be possible to start with the taking of anthropometric measurements for these participants (e.g. if 2 or 4 participants are waiting at the same time for the biological measurements, 2 of them may go to the staff taking the anthropometric measurements).

Note: Please read the test strip package inserts completely and carefully before testing. Use the test strip one time only. Only auto-disabling, single use lancing devices may be used with these devices. Dispose of properly.

For each test, the collected sample strips should be labeled with patient's initials, patient's unique identifier, the date of collection, and specimen types.

\section{I.I Fasting Glycaemia}

\begin{tabular}{|c|c|}
\hline I. Equipment & - $\quad$ Acutrend $®$ or CardioChek plus $®$ \\
\hline 2. Participant Preparation & $\begin{array}{l}\text { - Collect venous whole blood or capillary whole blood } \\
\text { from the fingertip. }\end{array}$ \\
\hline 3. Procedure & $\begin{array}{l}\text { - Set up the meter correctly. } \\
\text { - Insert the metallic end of the test strip into the meter. } \\
\text { - The meter turns on, 'Preparing to test' appears. } \\
\text { - When 'Apply drop' appears, obtain a blood drop. } \\
\text { - The test result appears on the display. } \\
\text { - Record the blood glucose result in } \mathrm{mg} / \mathrm{dL} \\
\text { - Remove and discard the used test strip by pulling the test } \\
\text { strip out of the meter or by pushing the test strip ejector } \\
\text { on the side of the meter. }\end{array}$ \\
\hline
\end{tabular}




\section{I.2 Fasting lipid panel}

\begin{tabular}{|c|c|}
\hline I. Equipment & $\begin{array}{l}\text { - Alere afinion } \mathrm{HbAlc} \text { or CardioChek plus } ® \text { (if available on } \\
\text { the site) }\end{array}$ \\
\hline 2. Participant Preparation & $\begin{array}{l}\text { - Collect venous whole blood or capillary whole blood from } \\
\text { the fingertip. }\end{array}$ \\
\hline 3. Procedure & 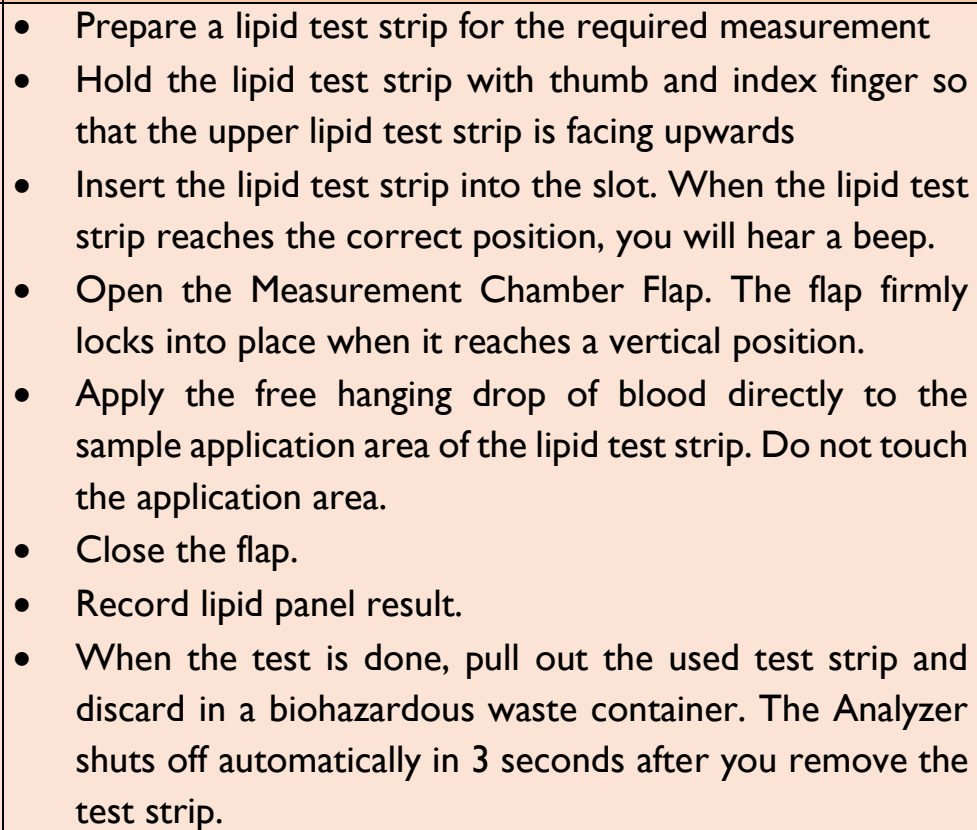 \\
\hline
\end{tabular}

\section{I.3 Glycosylated hemoglobin HbAlc}

\begin{tabular}{|c|c|}
\hline I. Equipment & $\begin{array}{l}\text { - Alere afinion HbAlc or DCA Vantage HbAlc Analyzer } \\
\text { SIEMENS } ® \text { (if available on the site) }\end{array}$ \\
\hline 2. Participant Preparation & $\begin{array}{l}\text { - Collect venous whole blood or capillary whole blood from } \\
\text { the fingertip. }\end{array}$ \\
\hline 3. Procedure & 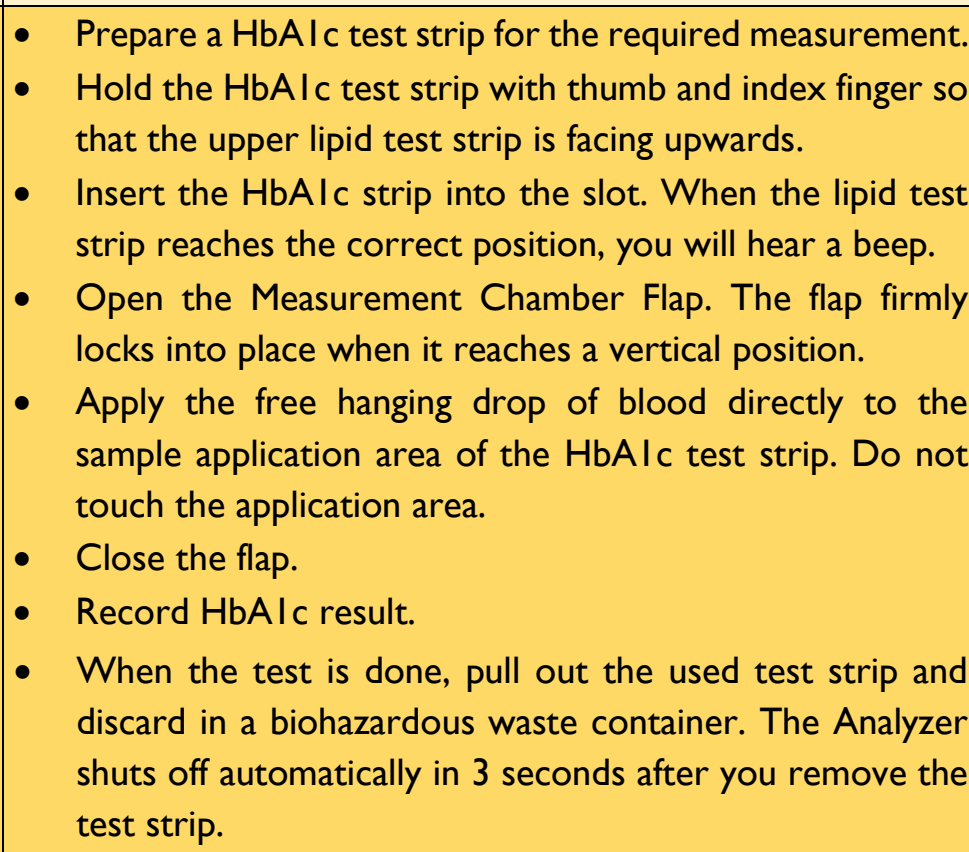 \\
\hline
\end{tabular}


Please note: For these tests, alternatives devices can be used depending on their availability. SRN sites for which POC equipment is not available can use local laboratories.

\section{I.4 Urine alcohol and five panel drug test}

\section{I.4.I The Collection Site}

The collection site should be safe and confidential to prevent unauthorized access to specimens, collection supplies, and data collection. A permanent site that is used solely for specimen collections should be secured at all times. At SRN sites that do not have a dedicated specimen collection site, the site used for specimen collections should be secured during the time a specimen is collected.

A collector must :

- Prohibit unauthorized staff from entering the collection site during the collection;

- Perform only one specimen collection at a time;

- Restrict access to collection supplies before and during the collection; and

- Ensure that only the collector and the participant are allowed to handle the unsealed specimen.

\section{I.4.2 Supplies}

The following items should be available at the collection site to conduct proper urine collections:

- $50 \mathrm{ml}$ cup for urine collection

- $10 \mathrm{ml}$ tube

- Test kits

- Calibrated timer

- Sterile towelettes

- Medical wastes disposal container 


\section{I.4.3 Collection procedures}

A clean-catch urine specimen is a sample of urine. A clean-catch specimen is a way of collecting urine that does not contain a lot of bacteria from the skin.

\begin{tabular}{|c|c|}
\hline Female & Male \\
\hline $\begin{array}{l}\text { I. Ensure urine container is labeled with } \\
\text { participant ID. } \\
\text { 2. Wash hands thoroughly in warm soapy } \\
\text { water and dry with a paper towel or allow } \\
\text { to air dry. } \\
\text { 3. Remove the urine container cap, taking } \\
\text { care not to touch the inside of the cap or } \\
\text { the inside of the container. } \\
\text { 4. Put the cap on the counter with the inside } \\
\text { of the cap face up. } \\
\text { 5. Open towelette. Separate the folds of the } \\
\text { urinary opening with fingers and clean } \\
\text { inside using one towelette, moving from } \\
\text { the front to the back. } \\
\text { 6. Clean one side and discard towelette. } \\
\text { 7. With a new towelette, clean the center } \\
\text { area and discard towelette. } \\
\text { 8. With a third new towelette, clean the } \\
\text { other side and discard towelette. } \\
\text { 9. Continue to hold the folds open and begin } \\
\text { urinating into the toilet. } \\
\text { 10. Bring the specimen container into the } \\
\text { urine stream and collect a "midstream" } \\
\text { specimen. Stop when the container is } \\
\text { approximately half full. } \\
\text { II. Finish urinating in the toilet. } \\
\text { I2. Tightly screw the cap on the container } \\
\text { taking care not to touch the inside of the } \\
\text { cap or the inside of the container }\end{array}$ & $\begin{array}{l}\text { I. Ensure urine container is labeled with } \\
\text { participant ID. } \\
\text { I. Wash your hands thoroughly in warm } \\
\text { soapy water and dry with a paper towel or } \\
\text { allow to air dry. } \\
\text { 2. Remove the urine container cap, taking } \\
\text { care not to touch the inside of the cap or } \\
\text { the inside of the container. } \\
\text { 3. Put the cap on the counter with the inside } \\
\text { of the cap face up. } \\
\text { 4. Open towelette. Retract foreskin (if } \\
\text { present) and use the towelette to clean the } \\
\text { entire head of the penis. } \\
\text { 5. Begin urinating into the toilet. } \\
\text { 6. Bring the specimen container into the urine } \\
\text { stream and collect a "midstream" specimen. } \\
\text { Stop when the container is approximately } \\
\text { half full. } \\
\text { 7. Finish urinating in the toilet. } \\
\text { 8. Tightly screw the cap on the container } \\
\text { taking care not to touch the inside of the } \\
\text { cap or the inside of the container. }\end{array}$ \\
\hline
\end{tabular}

\section{I.4.4 Testing procedures}

The SRN sites should use a urine rapid test to detect alcohol and substance use. Each site can use the test that is available in their country as the test consider the substances to be tested in the study. Refer to site test kits' instructions.

- Immerse the strip tips into the urine sample for 15 to 20 seconds.

- For each drug being tested, the result will be negative or positive.

- Negative test: Two red lines show up in the results area.

- Positive test: Only the (C) line appears. There is no (T) line.

Note: The urine alcohol test must be done at baseline, M6 and MI2. For the multipanel drug test, repeating this urine test at $\mathrm{M} 6$ and $\mathrm{MI} 2$ will be optional and at the convenience of each participating site if the baseline test reports no or limited drug use $(<2 \%)$ for one or more drugs.

The remaining urine must be send to the local laboratory for the constitution of a urine repository; I or 2 aliquots of $1.8 \mathrm{ml}$ stored at $-20^{\circ} \mathrm{C}$ or $-80^{\circ} \mathrm{C}$ according to local capacities. 


\section{I.4.5 Urine specimen collection: Trouble shooting}

\section{A- Insufficient specimen}

I. If the participant indicates that he or she may be able to provide a specimen if given more time:

- Offer the participant a reasonable amount of fluid to drink distributed reasonably through a period of up to 3 hours (e.g., an 8-ounce glass of water every 30 minutes, not to exceed 40 ounces over a period of 3 hours) or until the participant has provided a sufficient amount of urine, whichever occurs first.

- Ask the participant to let you know when he or she is able to provide a sufficient quantity of specimen. It is recommended that you allow sufficient time to have only one additional attempt rather than having to document several unsuccessful attempts. Be sensitive to how frequently you ask a participant to attempt to provide a specimen.

Note: The collector must NOT under any circumstances combine urine collected from separate voids to create one specimen of sufficient volume.

2. If the participant states that he or she is unable to provide a specimen, or if the participant has not provided sufficient volume of specimen in three hours from the time of the participant's first attempt, discontinue the collection and:

- Record the reason for not collecting the specimen on [CRF page].

3. If the participant refuses to attempt to provide a specimen or leaves the collection site before the collection process is completed, this is a refusal to test.

- Record on [CRF page].

\section{B- Refusal to test procedures}

The collector reports a "refusal to test" when:

I. The participant fails to cooperate with any part of the testing process (e.g., refuses to provide a specimen, refuses to display the items in his or her pockets at the beginning of the collection, or refuses to wash his or her hands at the beginning of the collection),

2. The participant declines to continue the collection process when his or her first specimen has insufficient volume,

3. The participant leaves the collection site before completion of the collection,

4. The participant admits to the collector that he or she has adulterated or substituted his or her specimen.

\section{I.5 HBV, HCV rapid diagnostic tests (Only at baseline)}




\begin{tabular}{|c|c|}
\hline I. Equipment & - Oraquick, (Orasure ${ }^{\circledR}$ ) or SD Bioline $\AA$ \\
\hline 2. Participant Preparation & $\begin{array}{l}\text { - Collect venipuncture whole blood, fingerstick whole } \\
\text { blood, plasma, or serum. }\end{array}$ \\
\hline 3. Procedure & $\begin{array}{l}\text { - You must use I test strip per test and make sure to keep } \\
\text { the lot number on the remaining strip pack. } \\
\text { - Add the participant's leDEA ID on the strip. } \\
\text { - Remove the protective film cover. } \\
\text { precision pipette and apply it to the absorbent pad of the } \\
\text { strip. } \\
\text { - Add one drop of reagent to the Specimen Diluent and } \\
\text { wait } 5-20 \text { minutes before reading the results. } \\
\text { - Visible test lines should be considered positive, even if } \\
\text { faint. } \\
\text { - The control line should appear for all results. If it does } \\
\text { not appear, the result is considered invalid and the } \\
\text { specimen should be retested using a new test kit. } \\
\text { - Record the result. }\end{array}$ \\
\hline
\end{tabular}

\section{I.6 Blood count/platelets, transaminases, creatinine (only at baseline)}

The study staff at the SRN site must supervise the performance and transfer of the various venous samples taken to the local laboratory according to the following procedure:

- A dry $5 \mathrm{ml}$ tube will be collect to perform the transaminase and creatinine assay.

- EDTA tubes will be used for the followings:

○ $5 \mathrm{ml}$ for the determination of complete blood count/platelets.

○ 5 or $10 \mathrm{ml}$ for the constitution of a plasma repository ( 1 or 2 aliquots of $1.8 \mathrm{ml}$, according to sites)

- For each participant, the collected tubes must imperatively contain the participant's first and last name, the date of collection and the leDEA identification number.

- Make sure that the EDTA tubes are properly mixed by turning (inverting) each tube ten times immediately after collection (do not shake the tubes to avoid cell lysis).

- A biological traceability sheet dedicated to this study must be filled in by the person taking the samples and enclosed with the tubes taken during transport to the local laboratory. This sheet will include the participant's unique identifier, the type and number of tubes collected, and the date and exact time of collection.

- Once collected, the tubes will be sent at room temperature within six hours after collection to the local laboratory.

- In order to facilitate the logistical organization of the project, the study staff/laboratory technician must optimize the number of venous samples taken in order to limit the number of trips for the transport of these tubes.

\section{I.7 Blood sampling using a DBS card (5 spots)}

A blood sample using a DBS card (prioritize Whatman 903 brand) will be taken from all participants in the SRN site. These samples will later be used for the quantification of HIV viral load and measures of additional biomarkers such as phosphatidylethanol (PEth).

Sampling shall be carried out according to the following procedures:

- Fill in all participant information on the DBS card (surname, first name, date of birth, etc...). 
- Fold the flap slightly so that the filter paper does not touch the paper during blood collection and avoid touching the blood collection circles.

- Choose a finger for the sample (index or middle finger recommended).

- Stimulate blood flow by briefly shaking your hand or massaging the finger several times from palm to fingertip.

- Clean the finger with alcohol and allow it to dry completely.

- Perform the capillary puncture with the incision device and gently wipe off the first drop of blood with a sterile compress or cotton ball.

- Wait for a large drop of blood to form and press it lightly against one side of the filter paper to allow the blood to completely fill the pre-printed circle.

- You must avoid any contact of the DBS card with the capillary puncture site.

- Repeat the procedure until all the circles are filled.

The DBS card must be left open at room temperature for 24 hours to allow the blood spots to dry completely. When the blood is completely dry, close the DBS card and place it in the envelope. The completed sample kit should be stored at room temperature and sent to the local laboratory within 24 hours of collection for storage at $-20^{\circ}$ or $-80^{\circ} \mathrm{C}$ at the local laboratories.

\section{I.8 Transport of specimen to the local laboratories}

Site will transport specimen to the local laboratories within 6 hours after collection in a suitable container in order to guarantee the quality of the analyses.

\section{I.9 Specimen storage (DBS, Blood and Urine) (at baseline)}

Plasma ( $\mathrm{I}$ or 2 aliquots of $1.8 \mathrm{ml}$ ), urine samples ( $\mathrm{I}$ or 2 aliquots of $1.8 \mathrm{ml}$ ) and DBS cards will be stored at local laboratories at $-20^{\circ} \mathrm{C}$ or $-80^{\circ} \mathrm{C}$, according to local capacity.

Note: Any information about specimen collected or storage such as volume collected, date of the collection should be recorded on the CRFs. 


\subsection{Participant's interview}

Interviews with participants of the study should be performed at baseline, M6 and MI 2 by study staff from the SRN sites.

Once the participants are formally included in the study (informed consent obtained), the study staff will be responsible for administering a structured questionnaire designed to collect data on the participant sociodemographic characteristics, locator information and alternative contact personal details as well as personal history of diabetes type 2, hypertension, dyslipidemia and chronic liver diseases. Other information includes coffee consumption or sodas or consumption of other sweetened beverage. Information potentially related to liver fibrosis/cirrhosis should be also collected such as the use of other selected medications (tuberculosis treatment, co-trimoxazole) associated with ARVs for preventive or curative purpose.

Chart review medical history should be also performed.

\subsection{Inclusion/ Exclusion}

Only participant who have $\mathbf{4 0}$ years old or older, three or more ARV drugs and received ART for 6 consecutive months or more are eligible to participate at the study.

Note: Participants who are pregnant are not eligible to participate.

Regarding question on date of birth: If unknown day, please enter "I5" for day, "June" for month if unknown month. If Date of Birth is not available, please enter the participant's age.

\subsubsection{Locator information and alternative contact personal details}

The study staff must collect all valid telephone numbers (ie.,2 personal numbers and I work phone) from each participant. It is recommended that the study staff ask the participants an alternative contact personal to reach them if necessary. At each follow-up visit, participants will be asked to verify these informations they provided at enrollment. Any changes will be recorded on the Form.

\subsubsection{Demographics}

All questions must be asked and in the order indicated.

Questions 3 and 4: Use one of the codes most appropriate to the participant's response as used in the local context.

Question 5: Use the equivalent of the local currency. All sources of household/family monthly must be included in the total household monthly income.

\subsubsection{Medical History (self-report)}

The study staff will ask questions related to medical history in a clear and concise language to be well understood by participants.

Question 5: Study staff can use any type of sodas or other sweetened beverages locally available and widely used.

\subsubsection{Chart Review Medical History}

The medical record review should be conducted at/around the time of the study visit. The SRN staff will be asked to report data such as medical history (diabete type 2, hypercholesterolemia, hypertrigyceridemia, hypertension, tuberculosis, liver diseases, viral hepatitis), treatment and laboratory (such as HIV viral load and CD4 count if available) data. 
Other measures potentially useful for subsequent analysis (e.g., most recent plasmatic albumin, alkaline phosphatase, gamma-glutamyl transpeptidase and bilirubin) should be extracted from medical records, if available.

For HIV viral load, please report the nearest measurement to the date of enrollment in SRN.

In case of missing information, the SRN staff will be asked to complete the requested data through following visits of participants.

Information should be reported in the specific section of the case report form entitled "Chart Review Medical History".

\subsection{Clinical Assessment}

A clinical assessment should be performed at M0, M6 and MI2 of the study and includes anthropometric measures such as height, weight, waist and hip circumference, blood pressure and heart rate.

An examination of the liver by Fibroscan ${ }^{\circledR}$ should also be performed.

\subsection{Anthropometric measures}

Ideally, these measures should be taken after the biological measures. Exceptionally, you may start with the anthropometric measurements if several participants are waiting for the biological measures.

\subsection{I.I Height}

\begin{tabular}{|c|c|}
\hline I. Equipment & $\begin{array}{l}\text { - Stadiometer/ Length Measuring Board } \\
\text { - Position the board/Stadiometer firmly against a wall surface }\end{array}$ \\
\hline 2. Participant Preparation & $\begin{array}{l}\text { - Ask the participant to remove their : } \\
\text { - } \quad \text { Footwear (shoes, slippers, sandals etc.) } \\
\text { - Head gear (hat, cap, bows, comb, ribbons etc.) } \\
\text { - Ask the participant to stand on the board/flat surface facing you } \\
\text { - } \text { Ask the participant to stand with: } \\
\text { - } \quad \text { Heet together } \\
\text { - Knees straight } \\
\text { - } \text { Ask the participant to look straight ahead and not tilt their head up } \\
\text { - Make sure eyes are the same level as ears } \\
\text { - } \text { Move the measure arm gently down onto the head of the } \\
\text { - Read the height in centimetres to the exact point } \\
\text { - } \text { Ask the participant to step away from the measuring board } \\
\text { Record the height measurement in centimetres }\end{array}$ \\
\hline
\end{tabular}




\begin{tabular}{|c|c|}
\hline I. Equipment & $\begin{array}{l}\text { - Portable electronic weighing scale } \\
\text { - Stiff wooden board to place under scale if surface is uneven } \\
\text { - Do not place on carpet, sloping, rough or uneven surface }\end{array}$ \\
\hline 2. Participant Preparation & $\begin{array}{l}\text { - Ask the participant to remove their } \\
\text { - Footwear (shoes, slippers, sandals, socks etc.) } \\
\text { - Ask the participant to step onto the scale with one foot on each side } \\
\text { of the scale } \\
\text { - Ask the participant to: } \\
\text { - Stand still } \\
\text { - Face forward } \\
\text { - Place arms on the side } \\
\text { - Wait until asked to step off } \\
\text { Record the weight in kilograms }\end{array}$ \\
\hline
\end{tabular}

\subsection{I.3 Waist circumference}

\begin{tabular}{|c|c|}
\hline I. Equipment & - Constant tension tape measure \\
\hline 2. Participant Preparation & $\begin{array}{l}\text { - This measurement should be taken without clothing, that is, directly } \\
\text { over the skin } \\
\text { - If not possible the measurement may be taken over light clothing } \\
\text { - It must not be taken over thick/ bulky clothes }\end{array}$ \\
\hline 3. Procedure & $\begin{array}{l}\text { - Standing on the side of the participant, locate the last palpable rib } \\
\text { and the top of the hip bone, making sure to wrap the tape over the } \\
\text { same spot on the opposite side } \\
\text { - Ask the participant to wrap the tension tape around themselves and } \\
\text { then position the tape at the midpoint of the last palpable rib and } \\
\text { the top of the hip bone, making sure to wrap the tape over the } \\
\text { same spot on the opposite side } \\
\text { NOTE: Check that the tape is horizontal across the back and } \\
\text { front of the participant and as parallel with the floor as possible } \\
\text { Ask the participant to: } \\
\text { - Stand with their feet together with weight evenly distributed across } \\
\text { both feet; } \\
\text { - Hold the arms in a relaxed position at the sides; } \\
\text { Breathe normally for a few breaths, then make a normal expiration }\end{array}$ \\
\hline
\end{tabular}




\begin{tabular}{|c|c|}
\hline I. Equipment & - Constant tension tape measure \\
\hline 2. Participant Preparation & $\begin{array}{l}\text { - This measurement should be taken without clothing, that is, directly } \\
\text { over the skin } \\
\text { - If not possible the measurement may be taken over light clothing } \\
\text { - It must not be taken over thick/ bulky clothes }\end{array}$ \\
\hline 3. Procedure & $\begin{array}{l}\text { - Stand to the side of the participant, and ask them to help wrap the } \\
\text { tape around themselves } \\
\text { - Position the measuring tape around the maximum circumference of } \\
\text { the buttocks } \\
\text { - As the participant to: } \\
\text { - Stand with their feet together with weight evenly distributed } \\
\text { over both feet } \\
\text { - Hold their arms relaxed at the sides } \\
\text { Check the tape position is horizontal around the body and snug } \\
\text { without constricting }\end{array}$ \\
\hline
\end{tabular}

\subsection{I.5 Blood pressure and heart rate measurements}

\begin{tabular}{|c|c|c|}
\hline I. Equipment & \multicolumn{2}{|c|}{$\begin{array}{l}\text { - Digital automatic blood pressure monitor - OMRON } \\
\text { - Appropriate size cuffs }\end{array}$} \\
\hline $\begin{array}{l}\text { 2. Participant } \\
\text { Preparation }\end{array}$ & 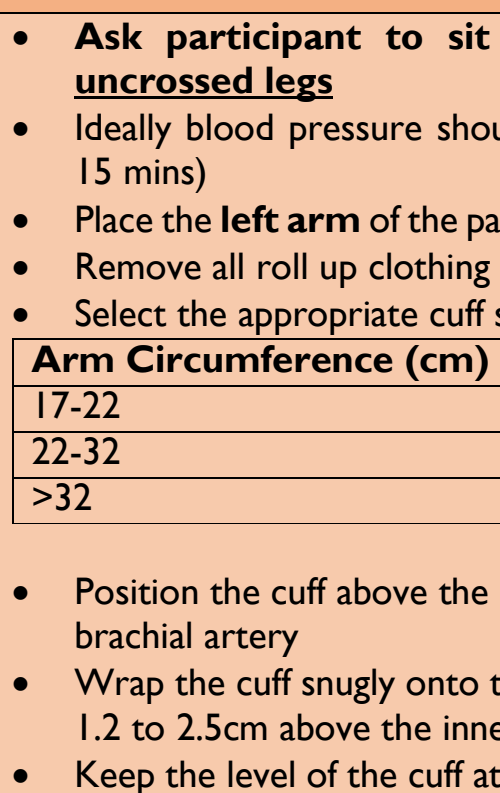 & $\begin{array}{l}\text { nd rest for at least I5 minutes with } \\
\text { be taken after enrolment questions (approx. } \\
\text { cipant on the table with the palm facing upward } \\
\text { the arm } \\
\text { using the following: } \\
\text { Cuff Size } \\
\text { Small (S) } \\
\text { Medium (M) } \\
\text { Large (L) } \\
\text { ow aligning the mark ART on the cuff with the } \\
\text { arm and the lower cuff edge should be placed } \\
\text { ide of the elbow joint } \\
\text { e same level as the heart during measurement }\end{array}$ \\
\hline $\begin{array}{l}\text { 3. Take Three } \\
\text { measurements }\end{array}$ & \multicolumn{2}{|c|}{$\begin{array}{l}\text { - THREE blood pressure measurements should be taken } \\
\text { - SWITCH OFF the monitor between readings, but leave the cuff in place } \\
\text { - The participant should rest for at least } 3 \text { MINUTES between each reading }\end{array}$} \\
\hline 4. Record Heart Rate & \multicolumn{2}{|c|}{$\begin{array}{l}\text { - Record the HEART RATE displayed on the monitor after each of the blood } \\
\text { pressure readings }\end{array}$} \\
\hline
\end{tabular}




\subsubsection{Liver stiffness and CAP measures (Fibroscan ${ }^{\circledR}$ )}

Liver stiffness measurement (LSM) and controlled attenuation parameter (CAP) will perform through the use of transient elastography (TE) with Fibroscan ${ }^{\circledR}$. It has been validated as a non-invasive method to assess liver fibrosis by LSM and steatosis by CAP. This test must be performed by experienced operators from the SRN sites (>50 examinations) following a validated procedure using an $M$ probe.

It is recommended to be done after the biological or anthropometric measures according to the following procedures.

\begin{tabular}{|l|l|}
\hline I. Material & $\begin{array}{l}\text { - } \\
\text { 2. Pabroscan }{ }^{\circledR} \text { using transient elastography (TE) }\end{array}$ \\
\hline 3. Procedures & $\begin{array}{l}\text { This test must be performed on an empty stomach } \\
\text { (three hours fast: Do not eat or drink). }\end{array}$ \\
- Note: Do not perform the test if participant has \\
any contraindications such as the presence of a \\
pacemaker, pregnancy or ascites.
\end{tabular}




\subsection{Screening questionnaires administration}

Questionnaires on mental health disorders, substance use should be administrated at M0, M6 and MI2 and the physical activity (CPAQ) should be administrated only at baseline by following these procedures. It is recommended that these questionnaires be administered to face-to-face by a social worker, sociologist or anthropologist of the SRN site. The approach will be provider-interview for all questionnaires.

\subsection{Mental Health disorders}

\subsection{I.I Patient health Questionnaire 9 (PHQ-9)}

\subsection{I.I.I Introduction}

The PHQ-9 is a multipurpose instrument for screening, diagnosing, monitoring and measuring the severity of depression. It incorporates DSM-IV depression diagnostic criteria with other leading major depressive symptoms into a brief tool. The PHQ-9 questionnaire contains 9 items and each of which is scored 0 to 3, providing 0 to 27 severity score. The questions 9 screens for the presence and duration of suicide ideation.

\subsection{Administration calendar}

This questionnaire should be administrated at M0, M6 and MI2 of the study.

\subsection{I.I.3 Administration procedures}

Before starting, the interviewer should discuss with the participants the reasons for completing the questionnaire. Each item asks participants whether they have been bothered by any of the symptoms during the previous two weeks.

Participants may provide only one of four possible answers:

- Not at all

0 point

- Several days I point

- More than half of the days 2 points

- Nearly every day 3 points

\section{PHQ-Scores and intervention algorithm}

Depression severity is graded based on the PHQ-9 score and presented below:

\begin{tabular}{|l|l|l|}
\hline PHQ-9 score & Depression severity & Intervention \\
\hline $0-4$ & None-minimal & None \\
\hline $5-9$ & Mild & $\begin{array}{l}\text { Refer to psychologist or designated clinic } \\
\text { staff member for counseling, follow up } \\
\text { and/or pharmacotherapy (if administrated } \\
\text { by someone else) }\end{array}$ \\
\hline$>10$ & Moderate to severe & $\begin{array}{l}\text { Refer to psychiatrist at/or nearest to the } \\
\text { SRN site }\end{array}$ \\
\hline
\end{tabular}




\subsection{I.I.4 Suicide risk assessment}

Some participants may reveal suicidal thinking during their participation in the study. If a participant reports anything other than "Not at all" to PHQ-9 question 9 or reports any other suicidal thinking or behavior, the study team member must implement the Suicide Risk Assessment Protocol (appendix 4) if no local standardized protocol is already available and applied in the participating SRN site. Otherwise, local suicide assessment and management protocols should apply. If a participant is determined to be a moderate or acute suicide risk through the suicide risk assessment, or otherwise reports active suicidal ideation or a suicide attempt, or presents with a drug reaction during a study visit:

a. The study staff member will personally escort the participant to the nearest psychiatric clinic or to a designated clinic staff member trained in the management of suicidal ideation and behavior

b. The study staff member, after ensuring that the participant is at the appropriate quarters for clinical management, will inform the site principal investigator within 24 hours. 


\subsection{I.2 Generalized Anxiety Disorder (GAD-7)}

\subsection{I.2.I Introduction}

The GAD-7 is an instrument for screening, diagnosing, monitoring and measuring the severity of anxiety disorder. The GAD-7 questionnaire contains 7 items. Each item asks the individual to rate the severity of his or her symptoms over the past two weeks. Response options include "not at all", "several days", "more than half the days" and "nearly every day". Each item is scored 0 to 3, providing 0 to 21 severity score.

\subsection{Administration calendar}

This questionnaire should be administrated at M0, M6 and MI2 of the study.

\subsection{Administration procedures}

Prior starting, the interviewer should discuss with the participants the reasons for completing the questionnaire.

\subsection{Interpretation of total score}

\section{Total score}

$1-4$

$5-9$

$10-14$

$|5-2|$

\section{Anxiety severity}

Minimal symptoms

Mild symptoms

Moderate symptoms

Severe symptoms

Please Note: The interviewer should refer the participant to the psychologist or designated clinic staff member for counseling if total score is 5 or greater and to psychiatrist designated clinic staff member if the total score is 10 or greater. 


\subsection{I.3 Post-Traumatic Stress Disorder}

\subsection{I.3.I Introduction}

The PCL-5 is a 20 -item measure that assesses the presence and severity of PTSD symptoms. Items on the PCL-5 correspond with DSM-5 criteria for PTSD. The PCL-5 can be used to quantify and monitor symptoms over time, to screen individuals for PTSD, and to assist in making a provisional or temporary diagnosis of PTSD.

\subsection{Administration calendar}

This questionnaire should be administered at M0, M6 and MI2 of the study.

\subsection{Administration procedures}

Before starting, the inteviewer should explain that they will be asking about problems that people sometimes have in response to a very stressful experience.

\section{- If the participant says 'No very stressful experience in the past month', you can} stop the interview.

The PCL-5 is intended to assess participant symptoms in the past month. Interviewer should ask to the participant to rate how bothered they have been by each of 20 items in the past month on a 5 point Likert scale ranging from 0-4. Items are summed to provide a total severity score (range $=0$ 80). 0 = Not at all; I = A little bit; 2 = Moderately; 3 = Quite a bit; 4 = Extremely.

A total score of 33 or higher suggests the participant needs further assessment with a specialist to confirm a diagnosis of PTSD. In that case, the interviewer can refer the participant to the psychologist or designated clinic staff member from the SRN site.

\subsubsection{Alcohol and Substance Use Disorder Screening}

\subsubsection{Alcohol Use Disorders Identification Test (AUDIT)}

\subsubsection{I.I Introduction}

This questionnaire on alcohol use disorder which contains 10 questions (PI-PI0) was developed by the World Health Organization (WHO) and has been used in a variety of health and social care settings. It allow to screen and identify people who are at risk of developing alcohol problems. The AUDIT test focuses on identifying the preliminary signs of hazardous drinking and mild dependence.

\subsection{Administration calendar}

This questionnaire will be administrated at M0, M6 and MI 2 of the study.

\subsection{Administration procedures}

Before starting, it is recommended that an explanation be given to participants of the content of the questions, the purpose for asking them, and the need for accurate answers. The following is illustrative introduction for oral delivery of the questionnaire:

"Now I am going to ask you some questions about your use of alcoholic beverages during the past year. Because alcohol use can affect many areas of health (and may interfere with certain medications such as ARV), it is important for us to know how much you usually drink and whether you have experienced any problems with your drinking. Please try to be as honest and as accurate as you can be." 
This statement should be followed by a description of the types of alcoholic beverages typically consumed in the local context (e.g., "By alcoholic beverages we mean your use of wine, beer, vodka, sherry, etc."). If necessary, include a description of beverages that may not be considered alcoholic, (e.g. cider, low alcohol beer, etc.). With participants whose alcohol consumption is prohibited by culture, or religion (e.g., observant Muslims), acknowledgment of such prohibition and encouragement of candor may be needed. For example, "I understand others may think you should not drink alcohol at all, but it is important in assessing your health to know what you actually do."

The interviewer should also clarify the meaning of a standard drink to participants. Questions 2 and 3 of AUDIT ask about "drinks consumed". The meaning of this word differs from one nation and culture to another. It is important therefore to mention the most common alcoholic beverages likely to be consumed and how much of each constitute a drink (approximately 10 grams of pure ethanol). For example, one bottle of beer $(330 \mathrm{ml}$ at $5 \%$ ethanol), a glass of wine (I40 ml at I $2 \%$ ethanol), and a shot of spirits ( $40 \mathrm{ml}$ at $40 \%$ ethanol) represent a standard drink of about I3 $\mathrm{g}$ of ethanol. Since the types and amounts of alcoholic drinks will vary according to culture and custom, the alcohol content of typical servings of beer, wine and spirits must be determined to adapt the AUDIT to particular settings. See Appendix 3.

It is important to read the questions as written and in the order indicated. By following the exact wording, better comparability will be obtained between your results and those obtained by other interviewers. Most of the questions in the AUDIT are phrased in terms of "how often" symptoms occur. Provide the participant with the response categories given for each question (for example, "Never," "Monthly or less," "2-4 times a month", ...). When a response option has been chosen, it is useful to probe during the initial questions to be sure that the participant has selected the most accurate response (for example, "You say you drink several times a week. Is this just on weekends or do you drink more or less every day?”).

If responses are ambiguous or evasive, continue asking for clarification by repeating the question and the response options, asking the participant to choose the best one. At times answers are difficult to record because the participant may not drink on a regular basis. For example, if the participant was drinking excessively during the month before an accident, but not prior to that time, then it will be difficult to characterize the "typical" drinking sought by the question. In these cases, it is best to record the amount of drinking and related symptoms for the heaviest drinking period in the past year, making note of the fact that this may be atypical or transitory for that individual. 


\subsection{Shortening the Screening Process}

If a participant says he or she abstain entirely from alcohol, the interviewer can stop to administer the complete AUDIT.

\begin{tabular}{|c|c|c|c|c|c|}
\hline Ouestions & 0 & 1 & 2 & 3 & 4 \\
\hline $\begin{array}{l}\text { 1. How often do you havo } \\
\text { a drink containing alcohol? }\end{array}$ & Never & $\begin{array}{l}\text { Monthly } \\
\text { or less }\end{array}$ & $\begin{array}{l}2.4 \text { times } \\
\text { a month }\end{array}$ & $\begin{array}{l}2-3 \text { times } \\
\text { a wook }\end{array}$ & $\begin{array}{l}4 \text { or more } \\
\text { times a woek }\end{array}$ \\
\hline $\begin{array}{l}\text { 2. How many drinks containing } \\
\text { alcohol do you have on a typicat } \\
\text { day when you are drinking? }\end{array}$ & 1 or 2 & 3 or 4 & 5 or 6 & 7 to 9 & 10 or more \\
\hline $\begin{array}{l}\text { 3. How often do you have six or } \\
\text { more drinks on one } \\
\text { occasion? }\end{array}$ & Never & $\begin{array}{l}\text { Less than } \\
\text { monthly }\end{array}$ & Monthly & Weekly & $\begin{array}{l}\text { Daily or } \\
\text { almost } \\
\text { daily }\end{array}$ \\
\hline $\begin{array}{l}\text { 4. How orten during the last } \\
\text { year have you found that you } \\
\text { were not able to stop drinking } \\
\text { once you had started? }\end{array}$ & Never & $\begin{array}{l}\text { Less than } \\
\text { monthly }\end{array}$ & Monthly & Weekly & $\begin{array}{l}\text { Dailly or } \\
\text { almost } \\
\text { daily }\end{array}$ \\
\hline $\begin{array}{l}\text { 5. How often during the last } \\
\text { year have you ralled to do } \\
\text { what was normally expected of } \\
\text { you bocause of drinking? }\end{array}$ & Never & $\begin{array}{l}\text { Less than } \\
\text { monthly }\end{array}$ & Monthly & Woestly & $\begin{array}{l}\text { Dailly or } \\
\text { atmost } \\
\text { daily }\end{array}$ \\
\hline $\begin{array}{l}\text { 6. How often during the last year } \\
\text { have you nooded a first drink } \\
\text { in the morning to get yourself } \\
\text { going arter a heavy drinking } \\
\text { session? }\end{array}$ & Never & $\begin{array}{l}\text { Less than } \\
\text { monthly }\end{array}$ & Monthly & Weokity & $\begin{array}{l}\text { Daily or } \\
\text { almost } \\
\text { caily }\end{array}$ \\
\hline $\begin{array}{l}\text { 7. How often during the last yoar } \\
\text { have you had a feelling of guilt } \\
\text { or remorse after drinking? }\end{array}$ & Never & $\begin{array}{l}\text { Less than } \\
\text { monthily }\end{array}$ & Monthly & Weosty & $\begin{array}{l}\text { Dailly or } \\
\text { almost } \\
\text { daily }\end{array}$ \\
\hline $\begin{array}{l}\text { 8. How often during the last yoar } \\
\text { have you boon unable to romem- } \\
\text { ber what happened the night } \\
\text { before because of your drinking? }\end{array}$ & Never & $\begin{array}{l}\text { Less than } \\
\text { monthly }\end{array}$ & Monthly & Wookty & $\begin{array}{l}\text { Daily or } \\
\text { almost } \\
\text { daily }\end{array}$ \\
\hline $\begin{array}{l}\text { 9. Have you ar someone else } \\
\text { boen injured bocause of } \\
\text { your drinking? }\end{array}$ & No & & $\begin{array}{l}\text { Yos, but } \\
\text { not in the } \\
\text { Last year }\end{array}$ & & $\begin{array}{l}\text { Yos. } \\
\text { during the } \\
\text { tast year }\end{array}$ \\
\hline $\begin{array}{l}\text { 10. Has a relative, friend, doctor, or } \\
\text { other heath care worker been } \\
\text { concerned about your drinking } \\
\text { or suggested you cut down? }\end{array}$ & No & & $\begin{array}{l}\text { Yes, but } \\
\text { not in the } \\
\text { last year }\end{array}$ & & $\begin{array}{l}\text { Yes } \\
\text { during the } \\
\text { last year }\end{array}$ \\
\hline
\end{tabular}

For question I, if the participant answers "Never" drinking has occurred during the last year, the interviewer may skip to Questions 9-10.

If the participant scored 0 on Questions 2 and 3, the interviewer may skip to Questions 9-10 because the participant's drinking has not exceeded the low risk drinking limits.

\subsubsection{I.5 Scoring}

- 0 to 7 indicates low risk

- 8 to 15 indicates increasing risk

- 16 to 19 indicates higher risk

- 20 or more indicates possible dependence

\section{Given feedback and advice}

If the score is $\mathbf{8}$ or above, give brief advice to reduce risk for alcohol harm. If the score is 20 or above, consider referral to specialist alcohol harm assessment.

\subsubsection{WHO Alcohol, Smoking and Substance Involvement Screening Test (ASSIST)}

\subsubsection{I Introduction}

The ASSIST questionnaire was developed by the WHO and contains 8 items. The ASSIST was designed to be culturally neutral and useable across a variety of cultures to screen for use of the following substance: tobacco products, alcohol, cannabis, cocaine, amphetamine-type stimulants (ATS), sedatives and sleeping pills (benzodiazepine), hallucinogens, opioids and 'other' drugs. The ASSIST contains 8 questions (PI-P8). 


\subsection{Administration calendar}

This questionnaire should be administrated at M0, M6 and MI2 of the study.

\subsection{Administration procedures}

During the introduction the interviewer should clarify which substances are to be covered in the interview and ensure that they are referred to by names which are familiar to the participant. The substances names on the ASSIST are those which are most commonly used in the countries in which the ASSIST was tested, but the interviewer should use the most culturally appropriate names for their location. The response card (Appendix 5) contains a list of the substance categories covered by the ASSIST together with a range of names associated with each category. It also contains frequency responses for each question. Each site must obtain this card and present it to the participant before asking the questions.

Every response for every drug and every question must be circled - including all zeros or negative responses, otherwise it may result in incorrect scoring.

Questions 2 through 5 ask about the frequency of events that have occurred in the last 3 months. The frequencies and their associated responses mean the following:

$\checkmark$ Never - means that the substance has not been used at all in the last 3 months (i.e. score $=$ 0);

$\checkmark$ Once or twice - means that the substance has been used a total of $I$ to 2 times in the last 3 months (i.e. score $=2$ );

$\checkmark$ Monthly - means the substance has been used an average of $I$ to 3 times per month in the last 3 months - resulting in a total of 3 to 9 times over the last 3 months (i.e. score $=3$ );

$\checkmark$ Weekly - means the substance has been used an average of $I$ to 4 times per week in the last 3 months (i.e. score $=4$ );

$\checkmark$ Daily / Almost daily - means the substance has been used an average of 5 to 7 days per week in the last 3 months (i.e. score $=6$ ).

- Question about which substance have ever been used in the participant's lifetime

Question I asks about lifetime use of substances, i.e., it is a good way to start talking to the participant about their substance use without being too intrusive, and also gives you a brief history of the participant's substance use. Every participant should be asked this question for all the substances listed. It concerns those substances the participant has ever used, even if it is only once.

It is a filter question, which means the answers recorded determine what happens next with regards to asking participants about specific drugs in the following questions.

If the participant answers 'no' to every substance, the interviewer should ask a probing question "Not even when you were in school?"

If the response is still 'no' to all the substances, then the interview is terminated. If the participant answers 'no' to certain substances only (for example, inhalants), the interviewer does not ask about that substance (i.e., inhalants) again in the ASSIST interview.

Through each substance group, remind the participant of what that substance category includes (for example, amphetamine-type stimulants include amphetamines, meth, speed and ecstasy) and also of any local terms for the substance including slang terms. Circle 'no' or 'yes' for each substance. 
Please Note: QI is not included to scoring.

- Question about the frequency of substance use in the past three months (Question 2)

If the participant answers 'yes' to question I for any of the substances listed, then move on to Q2 which asks about substance use in the previous three months. Q2 should be asked only for each of the substances ever used (as recorded in Q1). Q2 also is a filter question, which means the answers recorded determine what happens next with regards to asking participants about specific drugs in the questions 3, 4 and 5 .

If the response is 'never' to all of the items in Q2, that is, no substances have been used by the participant in the last 3 months, then move on to Q6.

If any substances have been used in the past three months then continue with questions 3,4 and 5 for each substance used.

Circle all responses, including the ' 0 ' responses - even for drugs not used ever, or not used in the last 3 months. May need to remind participant again of drug terms and names used of the local context. Remember coding definitions for the last 3 months (i.e. 'never', 'once' or 'twice', 'monthly', 'weekly', 'daily/almost daily').

If the participant cannot answer using the above terminology, the interviewer should calculate the appropriate frequency of use from the information they have given (for example, a participant who tells you that they have been smoking marijuana once every two weeks, you would need to re-interpret and score as 'monthly').

- Question about the frequency of experiencing a strong desire or urge to use each substance in the last three months (Question 3)

The interviewer should ask the participant only about the substances that he or she reported using in last 3 months (according to Q2). Some participants may be experiencing a strong desire or urge to use but have not used the substance in the last 3 months - but this would not be recorded by the ASSIST. For example, someone who stopped smoking cigarettes 5 months ago, but still experiences a strong desire to use cigarettes would not be recorded on Q3 because they have not smoked cigarettes in the last 3 months.

- Question about the frequency of health, social, legal or financial problems related to substance use in the last three months (Question 4)

For this question, it is important that interviewers be aware of the most common health, social, legal and financial problems associated with use of specific substances and mentions these as examples to prompt participants.

\section{For example:}

- For tobacco using participant you might say, "During the past 3 months how often has your use of cigarettes led to any health, social, legal or financial problems such as breathlessness, finding yourself less fit than usual, taking longer to recover from infections or financial problems because you don't have enough money to purchase what you need after buying cigarettes...?" 
- For alcohol using participants you might say, "During the past 3 months how often has your use of alcohol led to any health, social, legal or financial problems such as bad hangovers, vomiting, stomach pain, sleeping poorly, getting into arguments with people, drink driving, doing things while you are drunk that you later regret...?"

- For cannabis using participants you might say, "During the past 3 months how often has your use of marijuana led to any health, social, legal or financial problems such as forgetting to do things, difficulty paying attention or getting motivated, problems getting organized, feeling depressed or anxious...?"

- $\quad$ For participants using amphetamine-type stimulants you might say, "During the past 3 months how often has your use of amphetamines led to any health, social, legal or financial problems such as having a bad 'come-down' and feeling depressed, anxious and irritable the day or so after you have used, feeling angry, aggressive or uptight, getting headaches, sleeping poorly, dental problems from grinding your teeth...?"

- Questions about the frequency with which use of each substance has interfered with role responsibilities in the past three months (Question 5)

The interviewer may need to prompt the participant with examples of failed role obligations such missing work and losing pay or getting in trouble with the employer, having problems keeping up with work, poor work performance, negligence, losing job, missing school, college or university and falling behind, failing or doing poorly in assessments, or suspension or expulsion, failing to maintain usual family or relationship commitments, neglecting child caring activities, neglecting house cleaning or paying of bills, difficulty maintaining relationships with partner/friends/family or missing important family events, etc...

Tobacco is excluded from this question because, in general, people don't fail their role obligations because they are smokers.

- Questions about expressed concerns anyone else about the participant's use of each substance and how recently that occurred (Question 6)

All substances that were recorded when asked question I on lifetime use must be asked about in this question - not just those substances used in the last 3 months.

Concern can include things such as discussion, questioning, nagging, advice, worry, anger etc. by the other party to the participant.

Note: You will need to turn the questionnaire back to the front page to see what substances have been used in participant's life.

- Questions about participant's attempt to reduce or stop the use of a substance, and about the failure of that attempt, and how recently that occurred (Question 7)

All substances that were recorded when asked question I on lifetime use must be asked about in this question - not just those substances used in the last 3 months. 
This question contains multiple concepts and the interviewer can find it helpful to break down into 3 parts. For example:

1- Have you ever tried to cut down on smoking cigarettes? ('yes' or 'no')

2- Were you successful? ('yes' or 'no')

3- When was the last time you tried and weren't successful? ('never' or 'yes in the past 3 months' or 'yes, but not in the past 3 months')

If a participant has made several attempts to cut down and was successful eventually, the interviewer needs to record the last unsuccessful attempt. For example, someone that successfully stopped smoking cigarettes 3 months ago, but had several failed attempts prior to that would be recorded as 'yes, but not in the last 3 months'

Please Note: Participants can score 0 ('no, never') on this question only for 3 reasons:

I) Not necessary to cut down - i.e. don't use enough;

2) 'Happy' users (pre-contemplators) - i.e. don't want to cut down;

3) Have successfully cut down the first time they tried.

- Questions about injection of any substance and how recently how occurred (Question 8)

Note: The response to question 8 does not contribute to the final substance scores achieved by the participant.

If the participant has injected drugs in the last 3 months, the interviewer need to do the following:

1- Make a counselling on risk of injecting and procedures around safer injecting with the participant;

2- Ascertain the frequency and pattern of injecting in the last 3 months for the drug most frequently injected. The pattern of injecting will assist in determining whether the participant requires referral to specialist treatment.

If a participant says he or she injecting an average of more than 4 times per month over the last 3 months, the interviewer should referral him or her to specialist treatment nearest to the SRN site.

\subsection{Scoring of the ASSIST questionnaire}

As laid out in the ASSIST questionnaire, each participant will have 10 risk scores and can be recorded on the last page of the ASSIST questionnaire.

a- ASSIST risk score for tobacco (range $0-3 \mathrm{I}$ )

b- ASSIST risk score for alcohol (range 0 - 39)

c- ASSIST risk score for cannabis (range 0 - 39)

d- ASSIST risk score for cocaine (range 0 - 39)

e- ASSIST risk score for amphetamine-type stimulants (range 0 - 39)

f- ASSIST risk score for inhalants (range 0 - 39)

g- ASSIST risk score for sedatives or sleeping pills (range 0 - 39)

h- ASSIST risk score for hallucinogens (range 0 - 39)

i- ASSIST risk score for opioids (range 0 - 39)

j- ASSIST risk score for 'other' drugs (range 0 - 39). 


\subsubsection{Physical Activity}

\subsubsection{Global questionnaire on physical exercice (GPAQ)}

\subsubsection{I.I Introduction}

This global questionnaire on physical exercise (GPAQ) which contains 16 questions (PI-PI6) was developed by the World Health Organization (WHO) to investigate the practice of physical activity in different countries. It collects information on the practice of physical exercises in the following three situations: activities at work, moving from one place to another, leisure activities. One question evaluates on sedentary behaviors.

\subsection{Administration calendar}

This questionnaire will be administered only at baseline.

\subsection{Administration procedures}

Before starting, the interviewer should carefully read the annotated questionnaire, which will help him ask the questions and record the answers. All questions should be asked.

If the participant answers "no" to questions PI, P4, P7, PI0 or PI3, questions concerning the number of days and the duration will not be asked.

If you fail to ask one of the questions or if you delete one of the domains, the results you get will be more limited.

\section{- Questions about activities at work}

Read to the participant the introduction about the evaluation of activities at work.

For question I, the interviewer must define what he understands by "intense physical activities". Heavy physical activities are activities that require significant physical effort and cause a consequent increase in breathing or heart rate. Give the examples noted on the assignment sheet listed below and show the boards presenting these activities. Examples should be adapted to the local context.

For question 4, the examiner must define what he understands by "moderate-intensity activities". Moderately intense physical activities are activities that require moderate physical effort and cause a small increase in breathing or heart rate. Give examples noted on the handout and show the boards presenting these activities. Examples should be adapted to the local context.

For all the questions where you ask "how many days a week do you do physical activities (high intensity or moderate intensity) at work? ", the questions are about a normal work week and not the average that covers the period of the survey. Valid responses are between I and 7 .

For all the questions where you ask "how much time do you spend on these activities?", participants should consider the total amount of time they do intense or moderate physical activity on a typical day in a normal week. Respondents should only consider activities that are carried out for at least 10 consecutive minutes. Responses involving a significant duration (more than 4 hours) must be checked or confirmed to ensure that they correspond to a usual activity.

\section{- Questions about moving from one place to another:}


It is important to clearly state the introduction to the questions about moving from one place to another. This introduction is very important. It helps participants to think about how they move from one place to another.

For the question where you ask "how many days a week do you travel $[\ldots . .$. ?", valid responses are between I and 7 days.

For the question where you ask "how much time do you spend on walking or cycling?", participants should consider the total time they walk or cycle to move from one place to another on a typical day in a typical week for 10 minutes or more. Responses involving a significant duration (more than 4 hours) must be checked or confirmed to ensure that they correspond to a usual activity.

\section{- Questions about leisures or recreational activities}

The participant will think about his hobbies, which can also be called free time. Sport and physical activity are included, but not limited to competition. The activities taken into account must be practiced regularly and not from time to time. It is important to limit the participant only to leisure activities and not to include other activities already mentioned.

For question 10, the interviewer can recall what he understands by "intense physical activities". Give the examples noted on the assignment sheet and show the boards presenting these activities. Examples should be adapted to the local context.

For questions 12 and 15, when you ask “[...] how much time do you spend on it?", participants should consider the total amount of time they do intense physical activity during their leisure time. Participants should take into account only activities that are performed for at least 10 consecutive minutes. Responses involving a significant duration (more than 4 hours) must be checked or confirmed to ensure that they correspond to a usual activity.

For question 13, the interviewer can recall what he means by "moderate intensity physical activities" and give the examples noted on the assignment sheet and show the boards. Examples should be adapted to the local context.

\section{- Questions about sedentary behaviors}

- Read to the participant the introductory speech.

- In this part, there is only one question. Participants should consider the cumulative time spent sitting or lying down and give an estimate of the total time. Do not include time spent sleeping.

- Pay attention to the time reported by the participant.

- Do not hesitate to reconstruct the course of a usual day to assess the cumulative time spent sitting or lying down without sleeping. 


\subsection{Assignment sheet}

The are some examples of physical activity (to be adapted to the local context)

Physical Activity

Vigorous Physical Activity at Work

\section{Examples VIGOROUS Intensity Activities}

for vigorous activities at

Make you breathe much harder than normal WORK

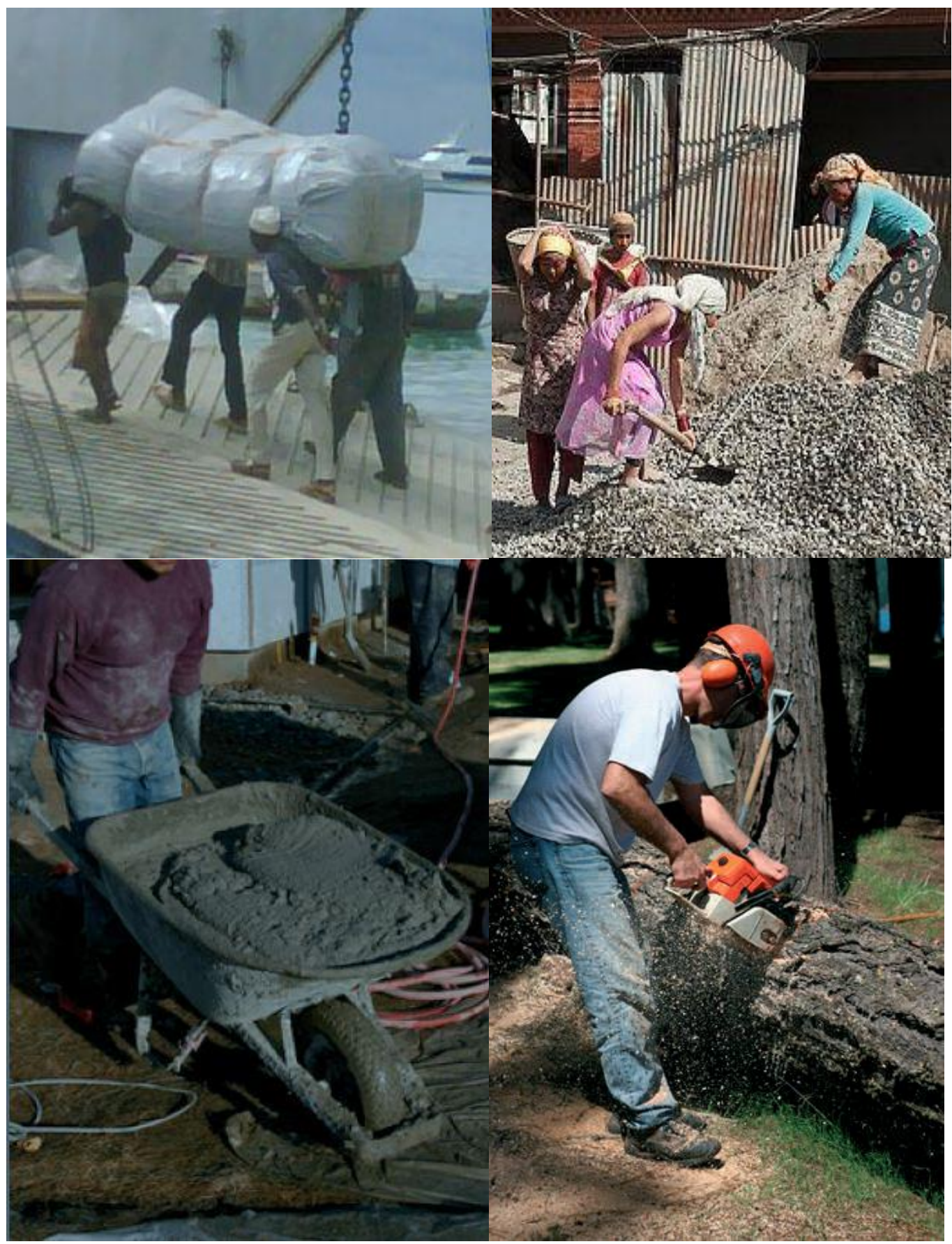


Other examples for VIGOROUS activities at WORK
- Forestry (cutting, chopping, carrying wood)

- Sawing hardwood

- Ploughing

- Cutting crops (sugar cane)

- Gardening (digging)

- Grinding (with pestle)

- Labouring (shovelling sand)

- Loading furniture (stoves, fridge)

- Instructing spinning (fitness)

- Instructing sports aerobics

- Sorting postal parcels (fast pace)

- Cycle rickshaw driving

Moderate Physical Activity at Work

\section{Examples for MODERATE activities at work}

MODERATE Intensity Activities

Make you breathe somewhat harder than normal
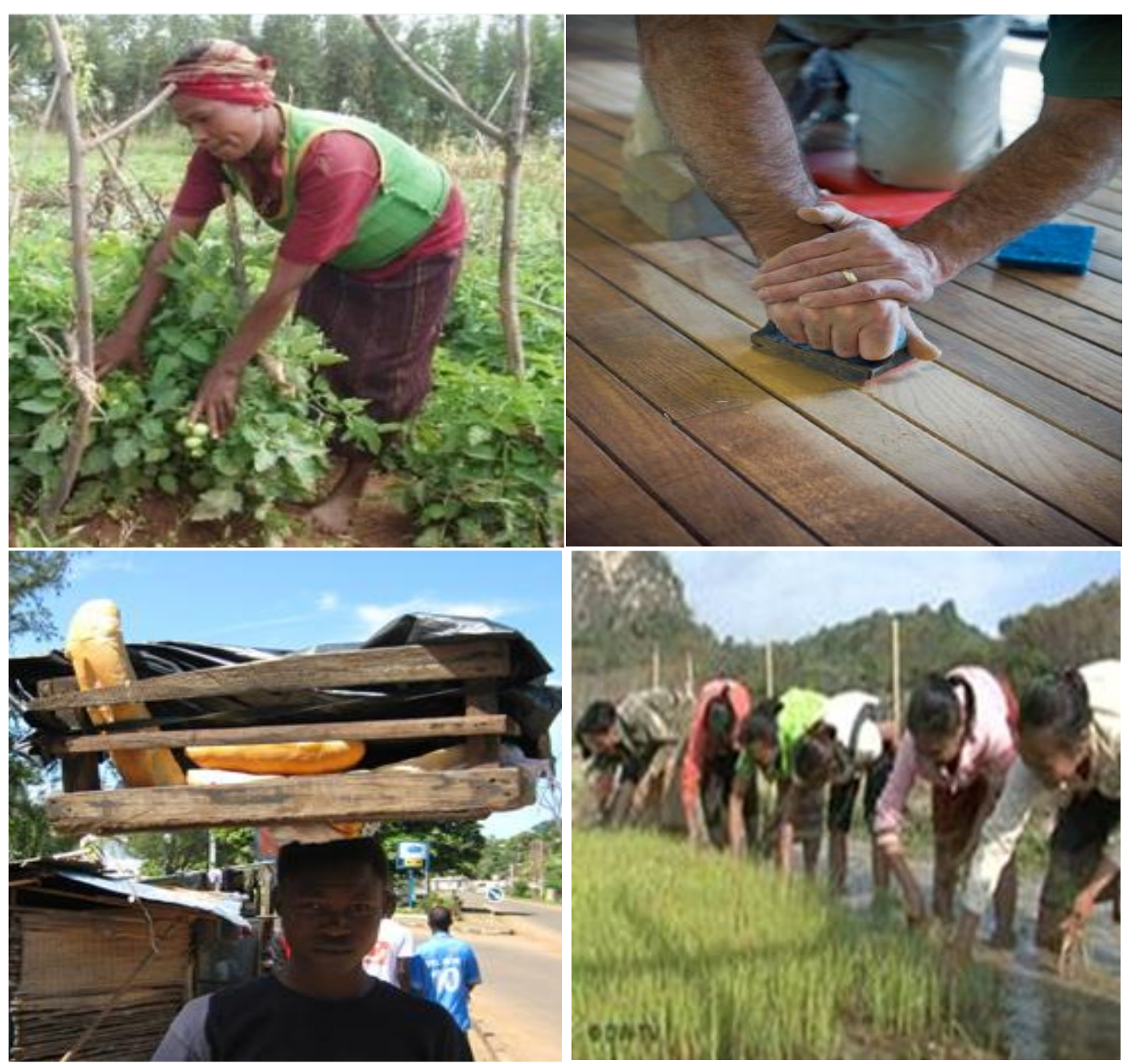
Other examples for MODERATE activities at WORK
- Cleaning (vacuuming, mopping, polishing, scrubbing, sweeping, ironing)

- Washing (beating and brushing carpets, wringing clothes (by hand)

- Gardening

- Milking cows (by hand)

- Planting and harvesting crops

- Digging dry soil (with spade)

- Weaving

- Woodwork (chiselling, sawing softwood)

- Mixing cement (with shovel)

- Labouring (pushing loaded wheelbarrow, operating jackhammer)

- Walking with load on head

- Drawing water

- Tending animals

Vigorous Physical Activity during Leisure or recreational Time

\section{Examples for} VIGOROUS activities during LEISURE TIME

\section{VIGOROUS Intensity Activities}

Make you breathe much harder than normal

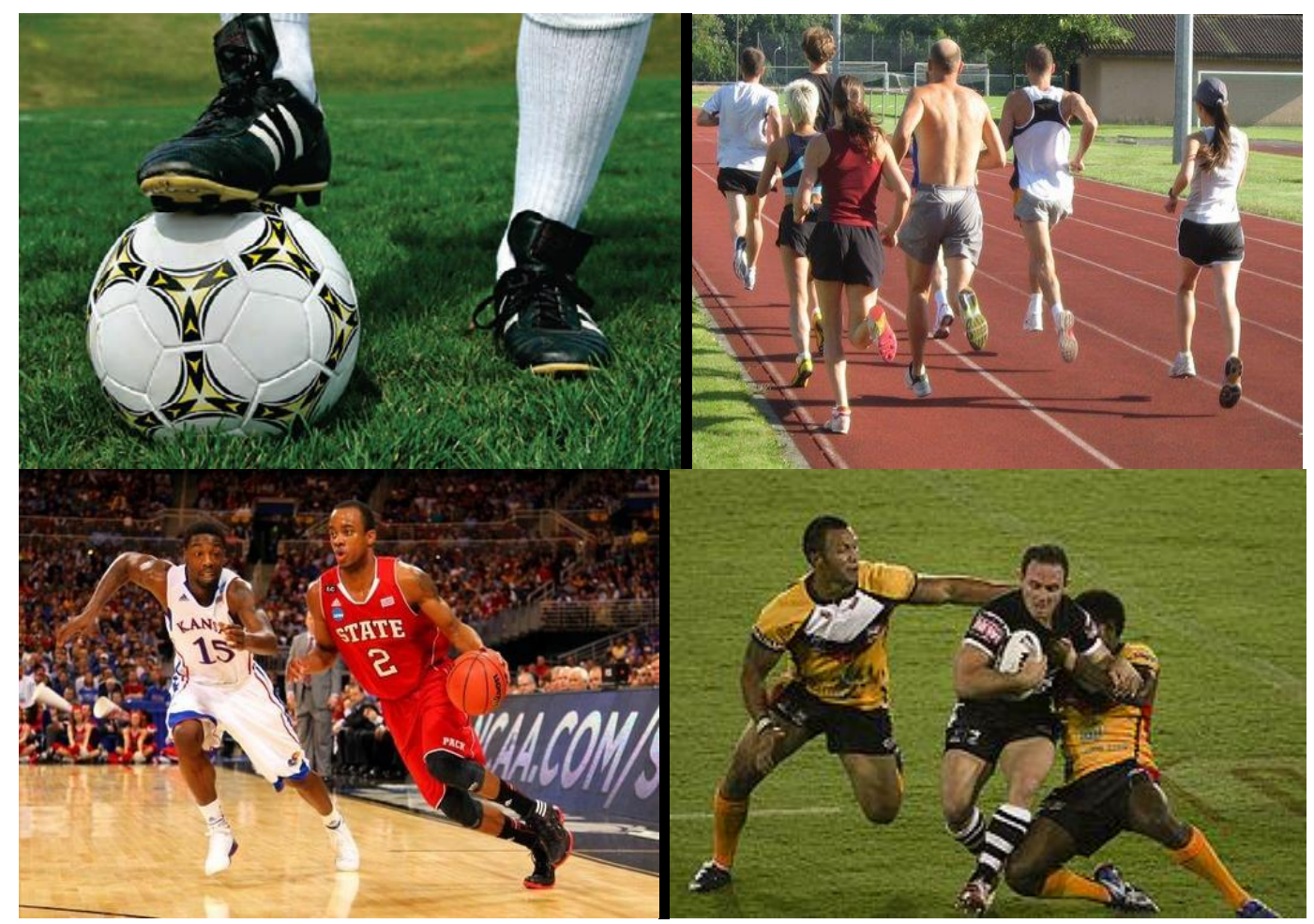

Other examples for VIGOROUS activities during LEISURE TIME
- Soccer

- Rugby

- Tennis

- High-impact aerobics

- Aqua aerobics

- Ballet dancing 
Moderate Physical Activity during Leisure Time

Examples for MODERATE activities during LEISURE TIME

Other examples for MODERATE activities at WORK

\section{MODERATE Intensity Activities}

Make you breathe somewhat harder than normal

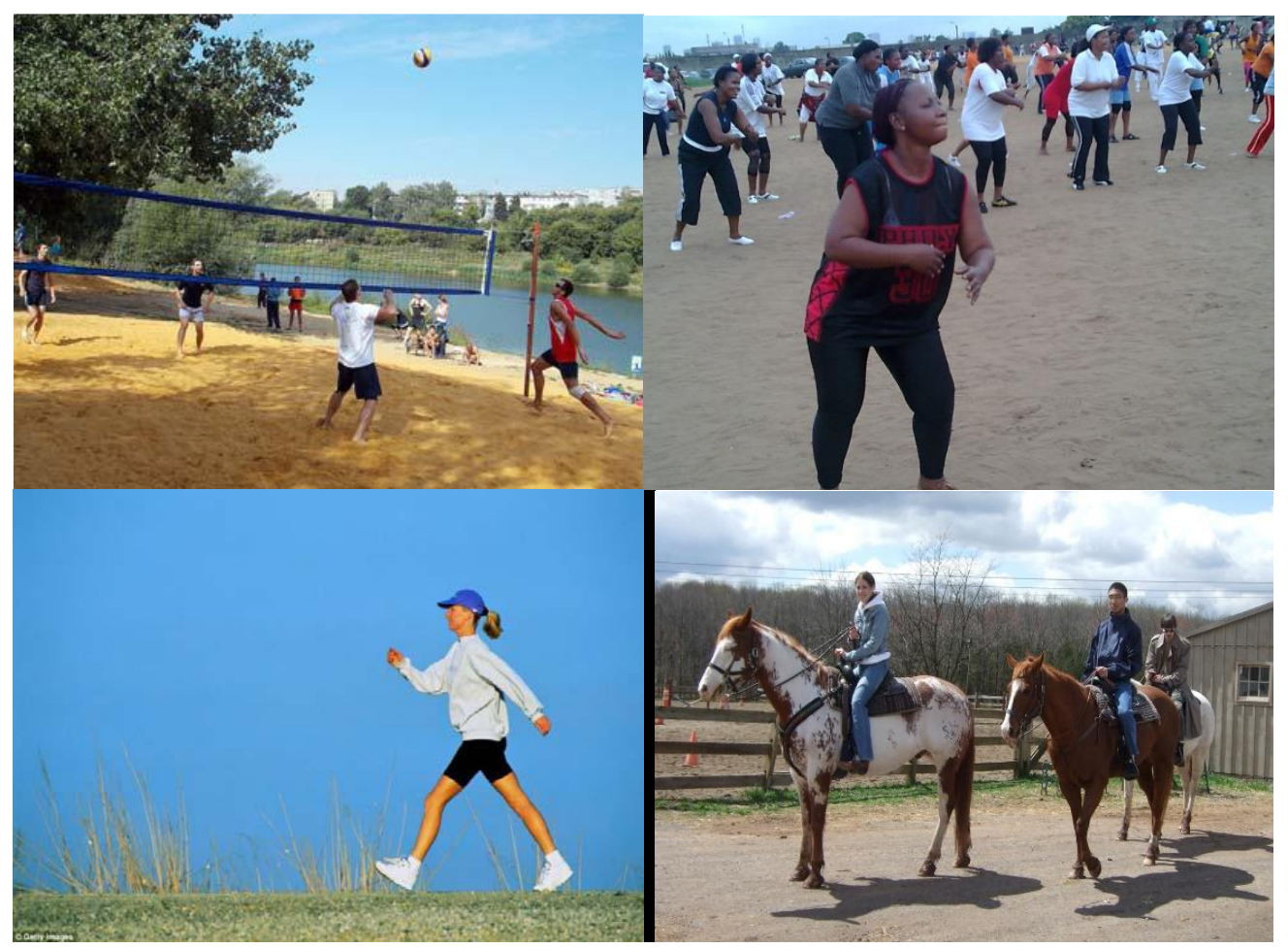

$>$ Cycling

$>$ Jogging

$>$ Dancing

$>$ Horse-riding

$>$ Tai chi

$>$ Yoga

$>$ Pilates

$>$ Low-impact aerobics

$>$ Cricket 


\section{$5 \quad$ Tracing process of participants between SRN visits}

All participants will have study visits at 6-month intervals for I year (i.e., 6, 12 months) after the date of enrollment.

Follow-up visits should be ensured within 4 weeks prior to or 4 weeks after each scheduled visit date. When trying to confirm or reschedule a follow-up visit, study staff will attempt to contact the participant at different times of the day, on different days of the week through the participant's preferred method of contact. If the study staff cannot reach the participant directly, they will get in touch with the alternative contacts listed in the Locator Form, if available. However, study staff will not identify the nature of the study in any messages, letters, or in communications with persons listed in the Locator Form.

Study staff will continue attempts to contact the participant until either the participant completes the follow-up visit, or three contact attempts have been made. Follow-up attempts will include text messages, phone calls, in-person visits or communications with the participant's contact(s) listed in the Locator Form.

If study staff exhausts all three contact attempts and the participant does not complete the follow-up visit, study staff will mark "Participant lost to follow-up" on the follow-up attempt form and no further attempts will be made to complete that follow-up visit. Study staff will use a follow-up attempt form to document each attempt to contact a participant, regardless of whether the contact is successful. If the attempts to contact a participant for the 6-month follow-up visit are unsuccessful, this same process will be repeated at the 12 -month follow-up visit.

Note: At the start of each follow-up visit, participants will be asked to verify the contact information they provided at enrollment. Any changes will be recorded on the Locator Form.

\section{Quality management plan}

For each SRN site, study site coordinator and study monitor will coordinate all follow-up activities for the study, under the direction of the project manager/coordinator. These activities include:

- Developing and monitoring workflows, timelines, milestones and progress measurement tools

- Organize regular team meetings to discuss project status, activities and to resolve issues that arise. These meetings can be face-to-face or distance meetings, depending on the distance

- Ensure adherence to protocol, procedures and Good Clinical Practice (GCP) and ensure data quality and query resolution.

\section{I SRN Study Quality Management Plan}

This Governance structure and the procedures established in the SRN project will facilitate the continuous monitoring and the quality assurance.

\section{Responsibility}

Project manager/coordinator has overall responsibility of implementing the quality management plan. The coordinator delegates this responsibility to the research staff of each SRN site.

Study site Coordinator/investigator and Study research staff are responsible for the quality control activities in the site.

$>$ Laboratory Staff is responsible for the quality control activities in the laboratory. 
$>$ Data Manager officer is responsible for the quality control activities in the Data Management Centre with the support of other staff.

$>$ Study site coordinator, study monitor and Data Manager are responsible for the quality control activities related to consent forms and CRFs.

$>$ Data Manager are responsible for Quality Assurance (QA) and Quality Control (QC) of all study documents (SDs) and filled CRFs.

$>$ Study Coordinator/Monitor/Data Manager are responsible for QA.

\section{I.I Quality Control (QC):}

$>$ Definition: It is the real time, ongoing (day-to-day) operational techniques and activities undertaken to verify the requirements for quality of the research related activities have been fulfilled.

> Responsibility: SRN study staff will be responsible for QC activities in the clinic. The data manager will be responsible for QC of all study documents and filled CRFs in the data center.

\section{Quality Control (QC) Process:}

A structured set of procedures will be followed from the time any study participant walks into the clinic.

\section{a) $\mathrm{QCI}$ :}

Inclusion/Exclusion criteria: The checklist will be prepared. Before enrolling the participants, the criteria will be checked by Study coordinator and Study staff for eligibility of the participant.

Informed Consent Form QC: Informed consent checklist will be prepared and filled by study staff. Real time self QC will be performed by study staff and will be reviewed by other staff for completeness. The patient will then be issued the Study Identification (ID). This patient after enrollment will be termed as the "Study Participant

$>$ The term "SELF-QC" in the clinic means to self-check each study document that is completed in clinic by the respective study staff for missing information before the study participant leaves the clinic. This process will ensure that none of the information will be missed out during the process of data collection.

$>$ CRF QC: The study staff will complete and self-QC their respective source documents/CRFs in the study area before the participant leaves the clinic. This process will ensure that none of the information will be missed out during the process of data collection. Study staff will make sure that all study related procedures are completed as per the protocol and all required SDs/CRFs are completed and will document their QC activities in the Visit Checklist which are study specific.

\section{b) QC2:}

QC2 will take place in the site data center.

> All CRFs required at a particular visit will be completed appropriately by the respective staff. The CRFs filled out on site using electronic pads by clinic staff member will be transferred daily to the REDCAP system in the site data centre. Informed consents will be kept in a binder at the clinic. For SRN sites who had initially collect data on paper in the first step, these data will be filed at the appropriate visit section of the participant binder. 
$>$ Data Manager and/or study monitor will QC 100\% of CRFs filled out on site for completeness and correctness before the data entry process for SRN site that collect data on paper. This QC will include but will not be limited to correct date, sign, skip logic and any clarifications or reasoning needed in the CRFs.

$>$ The CRFS which have gone through the QC process will either have a (I) Yellow Flag - for CRFs ready to be keyed into RedCap database or (2) Blue Flag - for any error found in the CRFs or if the information is non-compliant with the data previously available. This point is needed only for the site that data are collected on paper.

$>$ An electronic QA/QC log will be maintained by the Data Manager/study monitor to maintain a record of the $\mathrm{QC}$ done on daily basis. All the errors encountered during the $\mathrm{QC}$ process will be documented in this electronic log and communicated to the respective site staff for error resolution. Additional training will be provided by the QC team (Study site Coordinator/Data Manager/study monitor) to the study personnel who will summarize common errors encountered. This process will help in minimizing the errors.

\section{The 'Flagging' System:}

A 'Flagging' System will be used as a source of communication between the personnel completing CRFs and the Data Management team.

Four different colors of stick-on flags (tags) will be used:
$>$ Red
$>$ Green
$>$ Blue
$>$ Yellow

\section{Red means STOP}

This flag will be used by study team members who are responsible for completing the SDs/CRF. A red flag will mean "CRF" completion is pending". Once all the required documents/CRF are completed, all red flags will be replaced by green.

$>$ This will indicate that all questions in the source document/CRF are completed and a Self-QC is done.

\section{Green means GO- CRF ready for $\mathbf{Q C}$}

Used by the personnel completing SDs/CRF to indicate that all information is completed and self-QC is done. This will also indicate that the same is ready for second level of QC by the Data Manager/study monitor.

\section{Blue means PLEASE CORRECT}

- Used by the Data Management team to indicate that file has gone through a QC process and there are errors in the collected information and the CRFs needs to be corrected.

> Binders or folders containing these queries will go back to the personnel completing them for corrections. ALL the blue flags must be replaced with green flags to indicate that the information is corrected and ready to be rechecked (QC) and then captured/stored.

\section{Yellow means QC DONE}

$>$ These will be used by the QC team to indicate that the CRFs have passed the quality control procedures.

- For SRN site that data will be collect on paper, the data input manager should check that the data entered in the electronic system and that on the CRFs are correct and accurate before 
submission of e-data. On completion of data entry and submission of data to REDCAP's online data entry system. ALL the yellow flags will be removed by the personnel entering the data and the file will be handed to the Data Manager for secure storage.

Note : The flagging system will be used throughout the data management process.

\subsubsection{Quality Assurance (QA):}

$>$ Definition: It is a periodic, systematic and objective review of study-related activities to ensure that the study is performed and the data are generated, documented and reported in compliance with Good Clinical Practices and all the applicable regulatory requirements.

$>$ Responsibility: All member of the study team (Principal investigator/Project manager or coordinator/Study site coordinator/Data manager/study monitor/...) will be responsible for QA activities of the study.

\section{Quality Assurance (QA) Process:}

QA and QC are ongoing activities. Quarterly QA reviews will be study specific consist of randomly selected participants enrolled in the SRN study. This will be documented by the site Coordinator and data manager team and stored in the QA/QC reports binder. The error trends that are commonly repeated will be brought to the notice of the respective staff and appropriate training will be provided by the Data Manager team/study site coordinator.

\section{Priorities will be in the following order:}

I. New Protocols: First 5 enrollments for a new protocol will undergo a 100\% QA review.

2. Informed Consent: 100\% QA of informed consent procedures will be done with emphasis on time, date and correct signatures.

3. Eligibility Criteria: 100\% QA of inclusion and exclusion criteria.

\section{Corrective/Preventative Action Process:}

Once a problem has been identified from analysis of the QA or QC findings, it will be discussed with the study staff at the meeting organized as and when required. The root cause of a problem will be identified by discussions of the respective staff and $\mathrm{QC}$ team in the meeting. Actions will be taken to correct the problem based on the input from the site staff. These actions may include but are not limited to changing a process, giving appropriate training. Regular meetings will be conducted with site staff to resolve any issues and challenges.

\subsection{Closing visits of the study}

In each SRN site, closing visits will be completed by the Project investigator/project manager, study site investigator and the study monitor one month after the end of the follow-up. These visits are dedicated to:

- Retrieving and archiving consents.

- Recovery of remaining material.

- Correction of inconsistent or aberrant data.

- Recovery of missing data if possible. 


\section{Data management process}

The data management of the SRN study will be carried out by the data manager of each SRN study site. The process for completeness and consistency verification of the data will be specifically developed at each regional center. A data management plan should be written by the data manager to ensure proper data management.

As a reminder from the SRN protocol, the following paragraph presents the overall guidance form the Harmonist team who will support the SRN data collection and management.

The Harmonist team will provide support and tools for a standardized and harmonized data collection based on the common "Data Exchange Standard (DES)" already used in leDEA.

Data prospectively collected through the SRN will be coded in the DES format and merged with data previously collected within leDEA.

The Harmonist team will provide a "quick start" infrastructure for new data collection, secure data transfer, and data harmonization for the leDEA SRN projects. leDEA regions will be responsible for providing and maintaining their own computers and mobile devices, while the Harmonist team will provide the data collection application and associated training materials. Custom REDCap (a web and mobile-based data collections system widely used by leDEA) plugins will be developed for REDCap to DES data exports, and for auto-generated site status reports showing enrollment numbers, enrollment targets, data completeness, etc. As part of the quick start infrastructure, Harmonist will expand the DES to enable data harmonization and sharing of variables and data types introduced by the SRN. All survey instruments used in the SRN will be mapped to the Logical Observation Identifiers Names and Codes (LOINC) standardized terminology. An independent index to support other instruments used by the SRN will be maintained. To minimize post-collection data transformations, the Harmonist team will work with the SRN team to design paper-based data collection forms or CRFs that align with the variables defined in the DES. REDCap will be used to build an leDEA e-CRF library containing a compilation of REDCap electronic CRFs and data dictionaries. All CRFs will be created in English; leDEA regions will be responsible for translating the forms to their local languages. To ensure all SRN data ends up in DES, regardless of data capture methods, the Harmonist team will provide support to the sites using the quick start infrastructure and to the sites using alternative data collection methods. The workflow for collection and harmonization of the leDEA SRN is shown in Figure I (see protocol SRN). 


\section{Appendix}

\section{Appendix I: Standard Operating Procedure for Linguistic Validation}

The aim of linguistic validation of a questionnaires is to develop a scales in site specific local languages and to obtain a translation that is:

- conceptually equivalent to the original and comparable to local language

- culturally relevant

- easily understood by the people to whom the translated instrument is administered.

This validation process consists mainly of 4 steps:

I) Translation of scales in local languages

2) Review of translations by bilingual person, discussion among team, changes are made, then version I is ready

3) Cognitive Interviews with patients (4-5), discussion among team, changes in word or language if required and version 2 is ready.

4) In the interview with the participants, they are briefed about the purpose of this interview on questionnaires. Then they are asked about the questions' language and how comfortable they are answering these, do they understand the words and meaning in the questionnaire, do they have any suggestions to change the words in the questionnaire.

5) Proofreading of version 2, discussion and changes if any. Final version is prepared.

The report should be prepared based on the process by team members involved in it.

A linguistic validation process is a time-consuming process. Therefore sufficient time should be planned at each step of the translations, meeting with team, discussions, interviews with patients, discussions and production of reports. 
Appendix 2: List of required SRN devices6

\begin{tabular}{|c|c|c|c|c|}
\hline \multicolumn{5}{|c|}{ SUGGESTED SRN DEVICES } \\
\hline & TEST & $\begin{array}{l}\text { SUGGESTED } \\
\text { DEVICE }\end{array}$ & $\begin{array}{l}\text { ALTERNATIVE } \\
\text { DEVICE }\end{array}$ & SITE'S DEVICES \\
\hline \multirow{4}{*}{ 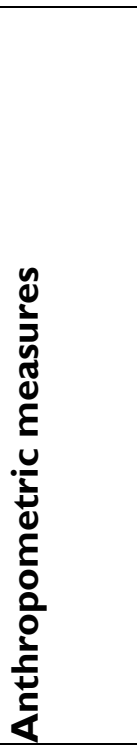 } & $\begin{array}{l}\text { Blood } \\
\text { Pressure/Heart } \\
\text { Rate }\end{array}$ & $\begin{array}{l}\text { Omron M3 Digital Blood } \\
\text { Pressure }\end{array}$ & $\begin{array}{l}\text { The suggested device is not } \\
\text { mandatory but sites need to } \\
\text { ensure that BP will be } \\
\text { measured by a calibrated } \\
\text { electronic device combined } \\
\text { with heart rate measure }\end{array}$ & - \\
\hline & $\begin{array}{l}\text { Waist, Hip } \\
\text { circumference }\end{array}$ & $\begin{array}{l}\text { Figure finder tape } \\
\text { measure }\end{array}$ & & - \\
\hline & Weight & GIMA electronic scale & $\begin{array}{l}\text { The suggested device is not } \\
\text { mandatory but sites need } \\
\text { to ensure that weight will } \\
\text { be measured by a calibrated } \\
\text { electronic device }\end{array}$ & - \\
\hline & Height & $\begin{array}{l}\text { Somatometre-Stanley } \\
04-116\end{array}$ & & - \\
\hline \multirow{3}{*}{ 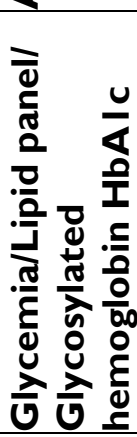 } & Glycemia & Acutrend $囚+$ strips & CardioChek plus $®+$ strips & $\begin{array}{l}\text { If POC device too } \\
\text { expensive or hardly }\end{array}$ \\
\hline & $\begin{array}{l}\text { Lipid panel } \\
\text { (including HDL- } \\
\text { Cholesterol) }\end{array}$ & $\begin{array}{l}\text { ALERE AFINION HbAlc } \\
\text { (HbAlc, lipid panel) + } \\
\text { kits reagents }\end{array}$ & & perform local standard \\
\hline & $\begin{array}{l}\text { Glycosylated } \\
\text { hemoglobin } \\
\text { HbAlc }\end{array}$ & & $\begin{array}{l}\text { DCA Vantage HbAIc } \\
\text { Analyzer (SIEMENS } ®)+ \\
\text { kits reagents }\end{array}$ & \\
\hline \multirow{2}{*}{ 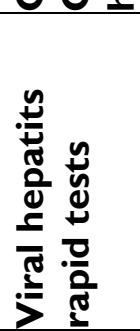 } & RDT HBV & Determine (Alere $\AA$ ) & SD Bioline HBV & \\
\hline & RDT HCV & Oraquick, (Orasure $®)$ & SD Bioline HCV & \\
\hline \multirow[b]{2}{*}{ 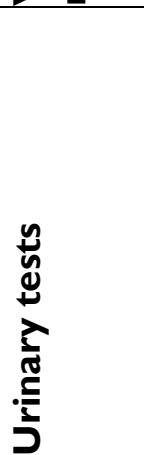 } & Alcohol & 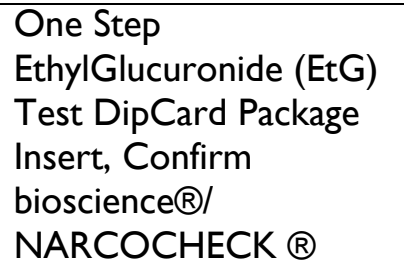 & & \\
\hline & Drug Panel & $\begin{array}{l}\text { Five Multi-Drug Panel } \\
\text { TestRapid } \\
\text { NARCOCHECK® }\end{array}$ & & \\
\hline
\end{tabular}




\section{What is a Standard Drink?}

In different countries, health educators and researchers employ different definitions of a standard unit or drink because of differences in the typical serving sizes in that country. For example,

- I standard drink in Canada: $13.6 \mathrm{~g}$ of pure alcohol

- I s drink in the UK: $8 \mathrm{~g}$

- I s drink in the USA: $14 \mathrm{~g}$

- I s drink in Australia or New Zealand: $10 \mathrm{~g}$

- I s drink in Japan: $19.75 \mathrm{~g}$

In the AUDIT, Questions 2 and 3 assume that a standard drink equivalent is 10 grams of alcohol. You may need to adjust the number of drinks in the response categories for these questions in order to fit the most common drink sizes and alcohol strength in your country.

The recommended low-risk drinking level set in the brief intervention manual and used in the WHO study on brief interventions is no more than 20 grams of alcohol per day, 5 days a week (recommending 2 non-drinking days).

\section{How to Calculate the Content of Alcohol in a Drink}

The alcohol content of a drink depends on the strength of the beverage and the volume of the container. There are wide variations in the strengths of alcoholic beverages and the drink sizes commonly used in different countries.

A WHO survey indicated that beer contained between $2 \%$ and $5 \%$ volume by volume of pure alcohol, wines contained $10.5 \%$ to $18.9 \%$, spirits varied from $24.3 \%$ to $90 \%$, and cider from $1.1 \%$ to $17 \%$. Therefore, it is essential to adapt drinking sizes to what is most common at the local level and to know roughly how much pure alcohol the person consumes per occasion and on average. Another consideration in measuring the amount of alcohol contained in a standard drink is the conversion factor of ethanol. That allows you to convert any volume of alcohol into grams. For each milliliter of ethanol, there are 0.79 grams of pure ethanol. For example,

- I can beer $(330 \mathrm{ml})$ at $5 \% \times$ (strength) 0.79 (conversion factor) $=13$ grams of ethanol

- I glass wine $(140 \mathrm{ml})$ at $12 \% \times 0.79=13.3$ grams of ethanol

- I shot spirits $(40 \mathrm{ml})$ at $40 \% \times 0.79=12.6$ grams of ethanol. 
Complete this form with all participants who answer anything other than "Not at all" on PHQ-9 question 9 or who otherwise reveal suicidal thinking during their participation in the study.

Refer to the Suicide Risk Assessment Protocol for guidance in completing this form.

Date (DD/MMM/YYYY)____ l__ leDEA Identifiant

\section{Differentiation of passive from active suicidal thoughts}

"In the last two weeks, have you had any thoughts of hurting yourself in some way?"

I - not at all 2 - several days 3 - more than half the days 4 - nearly every day

If “NOT AT ALL”: Very low risk (passive suicidal thoughts only). Skip to Section

III. OTHERWISE: Active suicidal thoughts. Continue with Section II.

II. Assessment of participants who demonstrate some evidence of active suicidal thinking.

1. "In the past month, have you made any plans or considered a method that you might use to harm yourself?" (circle one)

YES NO

(If yes, ask, "Please be specific about these plans or methods you have considered.")

2. "Have you ever attempted to harm yourself?" (circle one)

YES NO

(If yes, ask, “When was this? What happened?")

3. "There's a big difference between having a thought and acting on a thought. Do you think you might actually make an attempt to hurt yourself in the near future?" (circle one)

YES NO 
(If yes, ask, "Can you be specific about how you might do this?")

4. "In the past month have you told anyone that you were going to commit suicide, or threatened that you might do it?" (circle one)

YES NO

(If yes, ask, "Who have you told and what have you said to them?")

5. "Do you think there is any risk that you might hurt yourself before you see your doctor the next time? (circle one)

YES NO

(If yes, ask, “What do you think you might do?’)

If "NO" to ALL of Questions I-5: Active-Low Suicide Risk

If "YES" to any of Questions I-4, but NO to Question 5: Active-Moderate Suicide Risk

If "YES" to Question 5: Active-Acute (High) Suicide Risk.

\section{Summary of risk assessment. Check one.}

$$
\begin{aligned}
& \text { Passive (very low) _Active-Low _Active-Moderate _Active- } \\
& \text { Acute }
\end{aligned}
$$

\section{If Moderate or Acute Risk $\square$ Escort participant to clinician immediately.}

If Passive or Low $\square$ Continue with questionnaire. Include referral letter in chart and send participant to schedule follow-up appointment with designated clinic staff member after finishing interview.

Form completed by: 


\section{Response Card - SUBSTANCES}

a. Tobacco products (cigarettes, chewing tobacco, cigars, etc.)

b. Alcoholic beverages (beer, wine, spirits, etc.)

c. Cannabis (marijuana, dope, pot, grass, hash, etc.)

d. Cocaine (coke, crack, etc.)

e. Amphetamine-type stimulants (speed, ecstasy, meth, ice, paste, crystal, base, diet pills, etc.)

f. Inhalants (nitrous, NOS, glue, petrol, sprays, paint thinner, amyl, etc.)

g. Sedatives or Sleeping Pills (Valium, Serepax, Rohypnol, Normison, diazepam, temazepam, etc.)

h. Hallucinogens (LSD, acid, mushrooms, trips, Ketamine, etc.)

i. Opioids (heroin, opium, morphine, methadone, codeine, etc.)

j. Other - specify:

\section{Response card (ASSIST - Question 2-5)}

Never: not used in the last 3 months.

Once or twice: I to 2 times in the last 3 months.

Monthly: average of I to 3 times per month over the last 3 months.

Weekly: I to 4 times per week.

Daily or almost daily: 5 to 7 days per week.

\section{Response card (ASSIST - Question 6-8)}

No, Never.

Yes, but not in the past 3 months.

Yes, in the past 3 months. 